\title{
Sequence-specific promoter elements regulate temporal-specific changes in chromatin required for testis-specific activation of the Pgk2 gene
}

\author{
Zhangsheng Yang ${ }^{\dagger}$, Hirotaka Yoshioka ${ }^{\ddagger}$ and John R McCarrey \\ Department of Biology, The University of Texas at San Antonio, 1 UTSA Circle, San Antonio, Texas 78249, USA \\ Correspondence should be addressed to J R McCarrey; Email: john.mccarrey@utsa.edu \\ ${ }^{\dagger} \mathrm{Z}$ Yang is now at Department of Microbiology and Immunology, University of Texas Health Science Center at San Antonio, \\ 7703 Floyd Curl Drive, San Antonio, Texas 78229, USA \\ ${ }^{\ddagger} \mathrm{H}$ Yoshioka is now at Department of Calcified Tissue Biology, Institute of Biomedical and Health Sciences, Hiroshima University, \\ 1-2-3 Kasumi, Minami-ku, Hiroshima 734-8553, Japan
}

\begin{abstract}
The phosphoglycerate kinase-2 (Pgk2) gene is regulated in a tissue-, cell type-, and developmental stage-specific manner during spermatogenesis and is required for normal sperm motility and fertility in mammals. Activation of Pgk2 transcription is regulated by testis-specific demethylation of DNA and binding of testis-specific transcription factors to enhancer and core promoter elements. Here, we show that chromatin remodeling including reconfiguration of nucleosomes and changes in histone modifications is also associated with transcriptional activation of the Pgk2 gene during spermatogenesis. Developmental studies indicate that the order of events involved in transcriptional activation of the Pgk2 gene includes demethylation of DNA in $\mathrm{T}_{1}$ - and $\mathrm{T}_{2}$-prospermatogonia, binding of a factor to the CAAT box in type A and B spermatogonia, followed by recruitment of chromatin remodeling factors, displacement of a nucleosome from the Pgk2 promoter region, binding of factors to the Pgk2 core promoter and enhancer regions, and, finally, initiation of transcription in primary spermatocytes. Transgene studies show that Pgk2 core promoter elements are required to direct demethylation of DNA and reconfiguration of nucleosomes, whereas both enhancer and core promoter elements are required to direct changes in histone modifications and initiation of transcription. These results provide novel insight into the developmental order of molecular events required to activate tissue-specific transcription of the Pgk2 gene, the distinct elements in the $5^{\prime}$-regulatory region of the Pgk2 gene that regulate each of these events, and the relationship among these events in that each step in this process appears to be a necessary prerequisite for the subsequent step.

Reproduction (2013) 146 501-516
\end{abstract}

\section{Introduction}

Spermatogenesis is a highly ordered process by which the germ cell lineage gives rise to functional gametes in the male. As with other specific lineages in multicellular organisms, the characteristic differentiation of the male germ line proceeds as a result of expression of unique combinations of genes (Eddy 2002, Shima et al. 2004). Among the many germ cell type-specific genes expressed during spermatogenesis in mammals is a set encoding testis-specific glycolytic isozymes. These include the Ldhc, Gapdhs, Hk1s, Pgm2, Pdha2, and $P g k 2$ genes, each of which encodes sperm-specific isozymes of glycolytic enzymes (Fitzgerald et al. 1992, Mori et al. 1993, Eddy 2002, Boussouar \& Benahmed 2004, Tang et al. 2008).

Phosphoglycerate kinase (PGK) is a key enzyme involved in the metabolism of glucose via glycolysis.
In most mammals, PGK is encoded by two genes, $P g k 1$ and Pgk2 (VandeBerg et al. 1973, VandeBerg 1985, McCarrey \& Thomas 1987). Pgk1 is an X-linked gene that is ubiquitously expressed in all somatic cells, oogenic cells, and premeiotic spermatogenic cells (McCarrey et al. 1992). The autosomal Pgk2 gene is expressed in a tissue-, cell type-, and developmental stage-specific manner during spermatogenesis and is required for normal sperm motility and fertility (VandeBerg et al. 1973, McCarrey et al. 1992, Danshina et al. 2010). Because the spermatogenic cell lineage is particularly well characterized and accessible in mammals, it provides an excellent system in which to chronicle events leading up to activation of tissue-specific gene expression (McCarrey 1998).

Pgk2 transcription is first seen in primary spermatocytes, with transcript levels increasing throughout the 
first meiotic prophase and on into postmeiotic round spermatids (McCarrey et al. 1992). Transcription of this gene continues until midway through the process of spermiogenesis when the spermatid nucleus becomes so condensed that all transcription ceases (Kumari et al. 1996). We have previously demonstrated that a fragment carrying as little as $230 \mathrm{bp}$ of the Pgk2 5'-regulatory region is sufficient to direct proper tissue-, cell type-, and developmental stage-specific transcription of a reporter gene in transgenic mice (Robinson et al. 1989, Zhang et al. 1999), suggesting that this region contains sequence elements sufficient to direct all molecular changes required for properly regulated transcriptional activation of this gene. In addition, we characterized protein-DNA interactions associated with transcriptional activation of the $P g k 2$ gene and showed that the Sp3 factor is bound to a GC box in the Pgk2 core promoter and that $\mathrm{PBX} 4$, along with its co-activator, PREP1, is bound to the E3-E4 enhancer region immediately upstream of the $P g k 2$ core promoter in spermatogenic cells in which this gene is actively expressed (Yoshioka et al. 2007). Surprisingly, however, we found that a CAAT box, which is also present in the Pgk2 core promoter, is unbound in these same expressing cells, although we did observe an in vivo footprint at this element in earlier spermatogenic cell types (spermatogonia) prior to the onset of $P g k 2$ transcription (Yoshioka et al. 2007).

We have also examined changes in DNA methylation at the Pgk2 locus and found that a domain of demethylation begins to develop over the $P g k 2$ promoter region in $T_{1}$-prospermatogonia (McCarrey 2013) and becomes complete by the primitive type A spermatogonium stage (Geyer et al. 2004). This demethylation precedes transcription factor binding at the Pgk2 promoter/enhancer by several days (Geyer et al. 2004). Changes in DNA methylation are often associated with changes in chromatin structure (Robertson 2002), and at least two classes of chromatin modifications have been shown to contribute to regulation of transcription. One is ATP-dependent chromatin remodeling, which mobilizes nucleosomes by weakening the contacts between histone octamers and DNA, including transient unwrapping of the DNA from core histones or displacement of nucleosomes relative to specific landmarks in the promoter regions of genes, both of which enhance accessibility of key promoter elements to transcription factors (Becker \& Horz 2002, Flaus \& Owen-Hughes 2004, Smith \& Peterson 2005, Cairns 2009).

A second predominant type of chromatin modification involves post-translational modifications of histones, which include a variety of different types of modifications occurring on different amino acids in various positions within the core histones (Sterner \& Berger 2000, Jenuwein \& Allis 2001). Such modifications are particularly prominent on the $\mathrm{N}$-terminal tails of histones $\mathrm{H} 3$ and $\mathrm{H} 4$ and include lysine acetylation, lysine or arginine methylation, and serine or threonine phosphorylation among others (Berger 2002, Lachner et al. 2003, Kurdistani et al. 2004). These modifications can directly lead to altered structures of chromatin and/or can provide binding sites for regulatory proteins that further influence chromatin structure and transcription (Cairns 2009, Ho \& Crabtree 2010). In general, chromatin structure and nucleosome positioning have been found to be distinctly different in a tissue-specific gene in cell types in which the gene is actively expressed or terminally repressed respectively (Narlikar et al. 2002, Yuan et al. 2005, Mavrich et al. 2008, Schones et al. 2008), suggesting that these parameters are related to mechanisms regulating transcription.

The objectives of the study reported here were to i) examine histone modifications and nucleosome reconfiguration in the $P g k 2$ gene to identify features of chromatin structure that are unique to the actively expressed state of this gene, ii) determine the timing of appearance of these features relative to the timing of initiation of transcription of the $P g k 2$ gene during spermatogenesis and the timing of other molecular changes associated with activation of this gene, and iii) identify elements in the $5^{\prime}$-regulatory region of the $P g k 2$ gene that are involved in signaling or directing these chromatin changes. Our results indicate that there is an ordered series of molecular events that lead to activation of transcription of the $P g k 2$ gene in spermatogenic cells and that these events are signaled by distinct elements in the Pgk2 promoter/enhancer region. In addition, our data suggest that the occurrence of each of these events is largely dependent on the occurrence of the preceding event.

\section{Materials and methods}

\section{Generation of transgenic mice}

515Pgk2-CAT/WT and 188Pgk2-CAT transgenic mice (Mus musculus) were prepared for previous studies as described (Robinson et al. 1989). Three new lines of mice carrying a 515Pgk2-CAT/CAAT-minus transgene were generated for this study using similar procedures. The transgene used to generate these new lines was identical to that used for the 515Pgk2-CAT/ WT lines except that the CAAT box in the Pgk2 core promoter was mutated to ATCA by in vitro site-directed mutagenesis using recombinant PCR as described (Higuchi 1990, Barik 1996). The cesium chloride-purified, linearized transgene construct was introduced into early BDF1 (C57BI6×DBA2 F1 hybrid) embryos by pronuclear injection at the University of Texas Health Science Center at San Antonio transgenic mouse core as described previously (Nagy et al. 2003). Tail snips from pups were initially screened for transgene integration by PCR with specific primers shown in Supplementary Table 1, see section on supplementary data given at the end of this article, as described previously (Walter et al. 1989). PCR-positive mice were further confirmed as founders by Southern blot hybridization to genomic DNA from tail tissue (data not shown). 
Three transgenic founders $(\# 9, \# 10$, and $\# 20$ ) were identified and used to establish separate lines for the study described here.

\section{Preparation of cells}

Somatic spleen cells and spermatogenic germ cells for micrococcal nuclease (MNase) sensitivity and chromatin immunoprecipitation (ChIP) assays were recovered from either the transgenic mouse lines described earlier or from WT CD-1 mice purchased from Charles River Laboratories (Wilmington, MA, USA). All procedures involving live animals were approved in advance by the University of Texas at San Antonio Institutional Animal Care and Use Committee.

For isolation of spleen cells, spleens were dissected from freshly killed mice and placed in PBS and then mechanically teased open with hypodermic needles. The resulting cell suspension was filtered through $100 \mu$ m nylon mesh (Millipore, Billerica, MA, USA), then treated with hypotonic buffer to lyse any contaminating erythrocytes, and pelleted by centrifugation at $175 \mathrm{~g}$ for $10 \mathrm{~min}$ at $4{ }^{\circ} \mathrm{C}$.

For isolation of germ cells, testes were dissected from freshly killed prepuberal (6-8 days post partum (dpp)), puberal (18 dpp), or adult ( $\geq 60 \mathrm{dpp}$ ) CD-1 WT or BDF1 transgenic mice; decapsulated; and transferred into KREBS buffer (120.1 mM NaCl, $4.8 \mathrm{mM} \mathrm{KCl}, 25.2 \mathrm{mM} \mathrm{NaHCO}{ }_{3}$, $1.2 \mathrm{mM} \mathrm{KH}{ }_{2} \mathrm{PO}_{4}, 1.2 \mathrm{mM} \mathrm{MgSO} \cdot 7 \mathrm{H}_{2} \mathrm{O}, 1.3 \mathrm{mM} \mathrm{CaCl}$, $11.1 \mathrm{mM}$ glucose, $1 \mathrm{mM}$ glutamine, $10 \mathrm{ml} / \mathrm{l}$ of essential amino acids, $10 \mathrm{ml} / \mathrm{l}$ of nonessential amino acids, $100 \mu \mathrm{g} / \mathrm{ml}$ streptomycin, and $100 \mathrm{U} / \mathrm{ml}$ penicillin $\mathrm{G}\left(\mathrm{K}^{+}\right.$salt $)$) containing $0.5 \mathrm{mg} / \mathrm{ml}$ collagenase type 2 (Worthington) and incubated in a water bath for $15 \mathrm{~min}$ at $33^{\circ} \mathrm{C}$ with vigorous shaking. Cells from prepuberal or puberal testes were then collected by centrifugation at $175 \mathrm{~g}$ for $10 \mathrm{~min}$ at $4{ }^{\circ} \mathrm{C}$, while seminiferous tubule segments were collected from adult testes by pouring off the collagenase-containing KREBS buffer as described (Bellve 1993). The recovered cells or tubule segments were then washed with fresh KREBS buffer and incubated for another 15 min at $33{ }^{\circ} \mathrm{C}$ with vigorous swirling in KREBS buffer containing $0.5 \mathrm{mg} / \mathrm{ml}$ trypsin (Sigma). At the end of this incubation, $1 \mu \mathrm{g} / \mathrm{ml}$ DNase I was added and the cells were pipetted up and down repeatedly to dissociate the cells, and then filtered through $80 \mu$ nylon mesh to yield a single cell suspension. This yielded a 'mixed germ cell' population representative of the spermatogenic cell types present in testes at each age of male mice utilized.

To obtain purified populations of specific spermatogenic cell types, the mixed germ cell population derived from testes at each age was loaded onto a $2-4 \%$ BSA 'StaPut' gradient and the cells were allowed to sediment through the gradient at unit gravity for $4 \mathrm{~h}$ at $4{ }^{\circ} \mathrm{C}$ as described previously (McCarrey et al. 1992, Bellve 1993, Yoshioka et al. 2007). Primitive type A spermatogonia were isolated from testes of male mice at $6 \mathrm{dpp}$. Type A and type B spermatogonia were isolated from testes of $8 \mathrm{dpp}$ male mice. Preleptotene spermatocytes, leptotene plus zygotene spermatocytes, and early (juvenile) pachytene spermatocytes were isolated from the testes of $18 \mathrm{dpp}$ male mice. Pachytene spermatocytes, round spermatids, and elongated spermatids plus residual cytoplasmic bodies were isolated from the testes of adult ( $\geq 60 \mathrm{dpp}$ ) male mice.
Testicular spermatozoa were isolated from the testes of adult mice by dissociation of tissue and sonication to lyse all other cells. The purity of each cell population was determined by morphological examination under phase optics. Purities of spermatogonial cell types and juvenile spermatocytes were $\geq 85 \%$, while those of adult spermatocytes, spermatids, and spermatozoa were $\geq 95 \%$.

\section{Standard RT-PCR and real-time $q R T-P C R$}

For standard RT-PCR and real-time qRT-PCR assays, total cellular RNA was extracted from each cell population using TRIzol reagent according to the manufacturer's instructions (Invitrogen). The resulting RNA was quantified by Nanodrop (Thermo Scientific, Waltham, MA, USA). Before RT, $1 \mu \mathrm{g}$ total RNA was treated with 1 unit of RQ1 RNase-free DNase (Fisher Scientific, Hampton, $\mathrm{NH}$, USA) for $30 \mathrm{~min}$ at $37{ }^{\circ} \mathrm{C}$ to remove any DNA contamination. The RNA was then used as a template to synthesize first-strand cDNA using the iScript cDNA synthesis Kit (Bio-Rad) according to the manufacturer's instructions. To further control for the possibility of genomic DNA contamination, an additional first-strand cDNA synthesis reaction was conducted without $\mathrm{RT}$ and exposed to PCR amplification as a no-RT control.

RT-PCR was performed to detect the CAT transgene or the coding sequence of the constitutively expressed housekeeping gene, Gapdh. These target sequences were amplified using the RT-PCR primers shown in Supplementary Table 1. PCR products were resolved by electrophoresis through $1.5 \%$ agarose gels and visualized by ethidium bromide staining and detection on a VersaDoc imaging system (Bio-Rad).

For real-time qRT-PCR, first-strand CDNAs were amplified using SYBR Premix Ex Taq (Perfect Real Time) (Takara Bio, Inc. Otsu, Shiga, Japan) on a Chromo4 Continuous Fluorescence Detector (Bio-Rad) using the primers listed in Supplementary Table 1. Relative expression of target mRNAs and 18s rRNAs expressed as copy number was determined using a standard curve generated from DNA samples of known concentration.

\section{Bisulfite genomic sequencing of DNA}

To assess the status of DNA methylation at the $P g k 2$ promoter, we used bisulfite conversion followed by sequencing as described previously (Frommer et al. 1992, Clark et al. 1994). Total genomic DNA was extracted from germ cells or spleen cells using TRIzol reagent according to the manufacturer's instructions (Invitrogen). After quantification by Nanodrop (Thermo Scientific), 500 ng genomic DNA were treated with $130 \mu \mathrm{l}$ CT conversion reagent from the EZ DNA methylationGold Kit according to the manufacturer's instructions (Zymo Research Corporation, Irvine, CA, USA). Converted DNA was then purified using the QIAquick Gel Extraction Kit (Qiagen) and amplified using primers delineating the promoter or coding regions of the Pgk2 gene (Supplementary Table 1). Anticipated bands were excised from the $1.0 \%$ agarose gel and DNA was recovered using the QIAquick Gel Extraction Kit (Qiagen). The products were cloned into the TOPO TA cloning vector (Invitrogen) according to the manufacturer's instructions. Positive (white) colonies were selected and prepared for 
sequencing by the Nucleic Acids Core Facility at the University of Texas at San Antonio Health Science Center. The methylation status of each CpG dinucleotide was determined by comparison of sequences from amplimers of bisulfite-converted and untreated DNA respectively.

\section{MNase sensitivity assay}

An MNase sensitivity assay was used to map nucleosome positioning as previously described with minor modifications (Sekinger et al. 2005, Shim et al. 2007, Lam et al. 2008). Briefly, spleen or germ cells were isolated from transgenic (BDF1) or WT (CD-1) mice, washed three times with ice-cold PBS buffer, and resuspended in Tris-buffered saline prior to permeabilization with Tween 20 plus a proteinase inhibitor cocktail and phenylmethanesulfonyl fluoride (PMSF). Cells were then homogenized in a Dounce homogenizer using several strokes to release the nuclei, which were then pelleted and resuspended in digestion buffer $(0.32 \mathrm{M}$ sucrose, $50 \mathrm{mM}$ Tris- $\mathrm{HCl}$ (pH 7.5), $4 \mathrm{mM} \mathrm{MgCl}, 1 \mathrm{mM} \mathrm{CaCl}$, $0.1 \mathrm{mM}$ PMSF, and $5 \mathrm{mM}$ Na-butyrate) and incubated with the appropriate concentration of MNase (Sigma, N5386) at $37^{\circ} \mathrm{C}$. The reaction was stopped by adding SDS lysis buffer and proteinase $\mathrm{K}$ and incubating at $55{ }^{\circ} \mathrm{C}$ overnight, followed by extraction of the DNA with phenol/chloroform and precipitation in ethanol. Subsequently, the DNA was resuspended in TE buffer and RNase A was added and incubated for $30 \mathrm{~min}$ at $37^{\circ} \mathrm{C}$, followed by electrophoresis of the resulting mononucleosome DNA fragments through $1 \%$ agarose gel. The fragments were then recovered using a QIAquick Gel Extraction Kit (Qiagen) and redissolved in PCR grade water in preparation for real-time qPCR.

For analysis of MNase sensitivity in the endogenous $P g k 2$ gene and at Pgk2 transgenes, we used real-time qPCR with a series of primer pairs that delineated amplimers spanning the 5 -half of the Pgk2 gene, with each amplimer of $100 \pm 8 \mathrm{bp}$ representing regions of the gene located $40 \pm 10$ bp away from each other (Supplementary Table 1). The relative enrichment of target sequences was determined on the basis of copy numbers, which were calculated using a standard curve generated from DNA of known concentrations as described earlier.

\section{ChIP assay}

ChIP assays were performed using an immunoprecipitation assay kit (\#ab500; Abcam, Cambridge, UK) according to the manufacturer's instructions, with minor modifications. After isolation from mice, spleen and germ cells were fixed in a final concentration of $1 \%$ formaldehyde for $10 \mathrm{~min}$ at $37^{\circ} \mathrm{C}$ and then the reaction was stopped by adding $125 \mathrm{mM}$ glycine. After cells were washed once with PBS, the cells were lysed, the lysate was sonicated using a Branson Digital Sonifier (Branson Ultrasonics, Danbury, CT, USA) for 6 min with alternating $20 \mathrm{~s}$ on and $20 \mathrm{~s}$ off intervals at $45 \%$ amplitude, and with a longer pause every 2 min to cool down the samples. This sheared the chromatin to a fragment size range of $100-1000 \mathrm{bp}$. The sample was centrifuged to remove cell debris and immunoprecipitations were performed with antibodies against acetylhistone $\mathrm{H} 3$, acetyl-histone $\mathrm{H} 4$, and tri-methylation of lysine 4 of histone $\mathrm{H} 3$ ( $\mathrm{H} 3 \mathrm{k} 4 \mathrm{me} 3$ ) using antibodies from Active Motif. Antibody to rabbit IgG (Abcam) was used as a non-specific, negative control. After samples were incubated with antibody overnight at $4{ }^{\circ} \mathrm{C}$, protein $\mathrm{G}$ beads were added to pull down immunoprecipitated complexes, which were then washed with ChIP buffer (provided in the Abcam Kit), followed by DNA purification using the DNA purifying slurry (provided in the Abcam Kit) plus $1 \mu \mathrm{l}$ of proteinase $\mathrm{K}$ (provided in the Abcam Kit) to digest proteins following the kit instructions.

The resulting DNA was then analyzed by real-time qPCR on a Chromo4 real-time PCR detection system (Bio-Rad) using SYBR Premix Ex Taq (Perfect Real time, Takara Bio, Inc.). Relative amounts of DNA in the input and bound fractions were determined on the basis of copy numbers, using a standard curve generated from DNA samples of known concentration. Values for enrichment were calculated as the average of three independent samples.

\section{Results}

\section{Transgenic mice examined in this study}

Three different transgenes were used in this study (Fig. 1B). These included a construct carrying $515 \mathrm{bp}$ of $5^{\prime}$-flanking sequence from the human Pgk2 gene including the $P g k 2$ core promoter plus the E1/E2 and E3/E4 enhancer regions (515Pgk2-CAT/WT). We have previously shown that this transgene is expressed in the same tissue-, cell type-, and developmental stagespecific manner as the endogenous mouse Pgk2 gene, indicating that all regulatory information required to direct this transcriptional pattern is included in this fragment of the Pgk2 gene (Robinson et al. 1989, Zhang et al. 1999). This reflects the fact that both the human and mouse Pgk2 gene promoters contain highly conserved regulatory elements including a GC box, a CAAT box, and an enhancer region just upstream from the CAAT box (McCarrey 1987, 1990). A second transgene (188Pgk2-CAT/WT) carried the human Pgk2 core promoter but not the upstream E1/E2+E3/E4 enhancer region. This transgene is not expressed in any tissue in transgenic mice, including spermatogenic cells (Robinson et al. 1989, Zhang et al. 1999). To investigate the function of the CAAT box in the Pgk2 core promoter, we produced three new lines of transgenic mice carrying a transgene identical to the 515Pgk2-CAT/WT transgene except that the CAAT box was mutated from CAAT to ATCA (515Pgk2-CAT/CAAT-minus). Because this transgene carries all other sequence information normally required to direct properly regulated transcription of the Pgk2 gene, this construct allowed us to focus on the function of the CAAT box in this process. Importantly, as noted in our previous studies (Robinson et al. 1989, Zhang et al. 1999), expression of the promoter-reporter transgene, which encodes the prokaryotic chloramphenicol acetyl transferase enzyme, imposes no measurable phenotypic effects on testis or systemic functions or characteristics in the transgenic mice. 


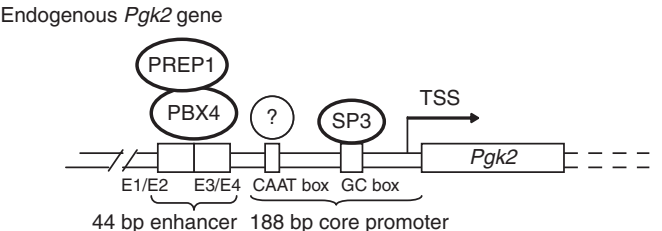

B

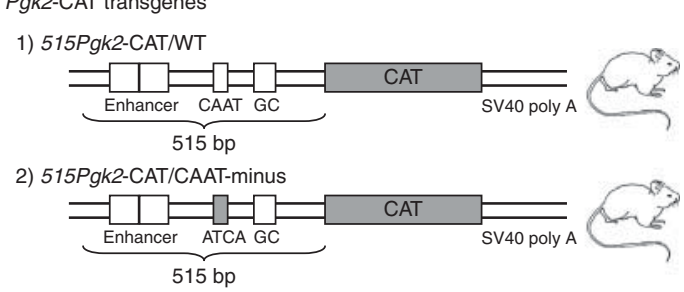

3) $188 \mathrm{Pgk} 2-\mathrm{CAT}$

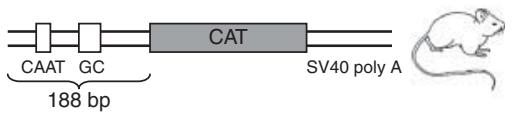

C RT-PCR

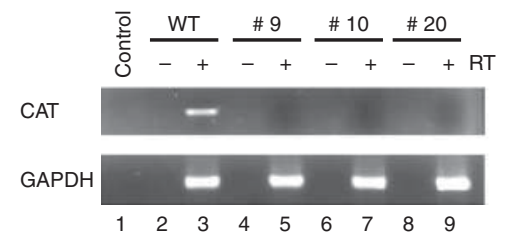

D $\quad$ qRT-PCR

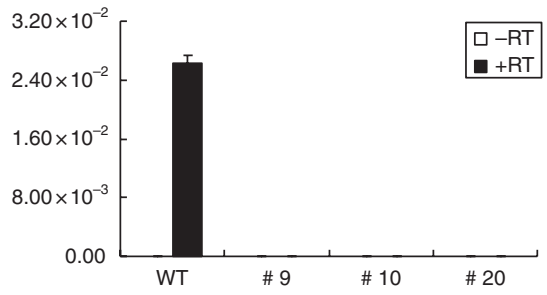

E Pgk2 CpG map

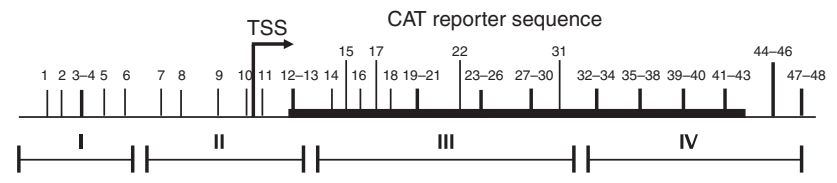

F Testis CpG methylation
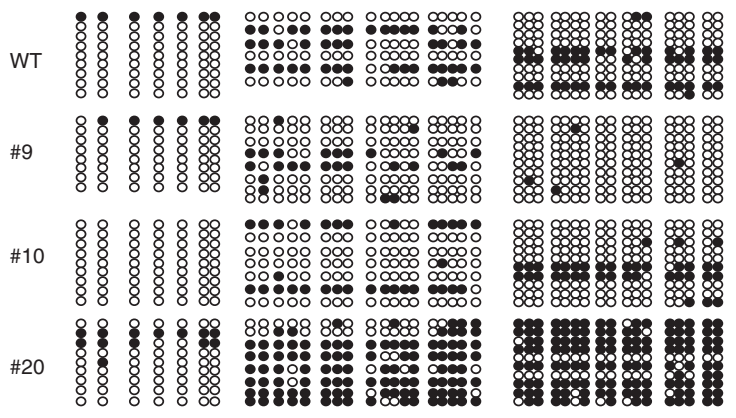

G Spleen CpG methylation
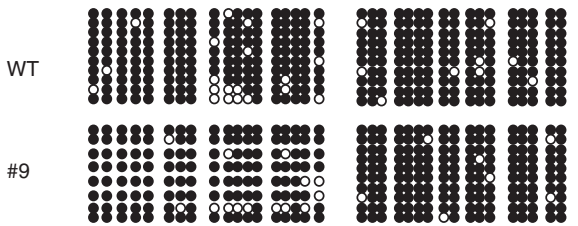

\#10

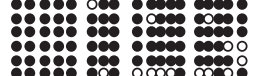

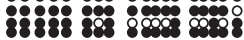
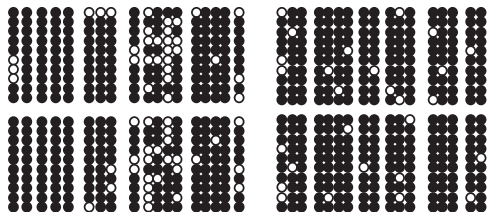

Figure 1 Effects of disruption of the Pgk2 CAAT box on transcription and demethylation of the Pgk2 gene. (A) A map of the $5^{\prime}$ regulatory region of the Pgk2 gene is shown. A 188-bp core promoter includes the transcription start site (TSS) at the +1 position, a GC box at -30 to -22 , and a CAAT box at -105 to -101 . A 44-bp enhancer region lies immediately upstream from the core promoter and includes two subregions, E1/E2 and E3/E4. In cells actively expressing the Pgk2 gene, the Sp3 factor is bound to the GC box in the core promoter and the PBX4 transcriptional activator and its CO-activator, PREP1, are bound to the E1/E2 portion of the enhancer region. Prior to initiation of transcription (but not during transcription), an unknown factor (?) is bound to the CAAT box. (B) Three different transgenes were used for this study: 515Pgk2-CAT/WT-a transgene that includes the WT core promoter and enhancer region sequences, 515Pgk2-CAT/CAAT-minus - a transgene identical to the 515Pgk2-CAT/WT transgene except that the CAAT box has been mutated to ATCA, and 188Pgk2-CAT - a transgene that includes the WT Pgk2 core promoter sequence but lacks the enhancer region. Mice carrying the 515Pgk2-CAT/WT and 188Pgk2-CAT transgenes were generated for a previous study (Robinson et al. 1989), whereas three lines carrying the 515Pgk2-CAT/CAAT-minus transgene were generated for this study. All transgenes were composed of human Pgk2 promoter fragments ligated to the bacterial chloramphenicol acetyltransferase (CAT) reporter gene plus the simian virus 40 (SV40) 3'-UTR poly(A) addition sequences. The 515Pgk2-CAT/WT transgene showed strong expression in mouse testis (WT); however, the 515Pgk2-CAT/CAAT-minus showed no detectable expression in testis tissue from any of the three lines carrying this transgene ( $\#$, $\# 10$, and $\# 20$ ) as measured by either standard RT-PCR (C) or qRT-PCR (D). A map of the $5^{\prime}$ half of the Pgk2 gene (E) shows the locations of 42 CpG dinucleotides and the four amplicons, I, II, III, and IV, used to analyze DNA methylation at these sites by bisulfite genomic sequencing analysis of testis tissue (F), or somatic spleen tissue (G) from each line. Unmethylated CpGs are represented as open circles, whereas methylated CpGs are represented as filled circles. Each row of circles represents analysis of a different original DNA strand. The 515Pgk2-CAT/WT line and all three 515Pgk2-CAT/CAAT-minus lines showed complete or partial demethylation in testis tissue but remained hypermethylated in spleen tissue. GC, GC box; CAAT, CAAT box; ATCA, mutant sequence substituted for the CAAT box in the 515Pgk2-CAT/CAAT-minus transgene.

\section{The CAAT box in the Pgk2 core promoter is required for initiation of transcription}

We used RT-PCR to examine expression of the 515Pgk2CAT/WT and 515Pgk2-CAT/CAAT-minus transgenes in testis RNA (Fig. 1C). As expected, we confirmed expression of the 515Pgk2-CAT/WT transgene in testis tissue. However, the 515Pgk2-CAT/CAAT-minus transgene was not expressed in testis tissue recovered from males of any of the three different lines we generated carrying this transgene $(\# 9, \# 10$, and $\# 20)$. This indicates 
that activation of transcription cannot occur in the absence of an intact CAAT box in the $P g k 2$ core promoter. To confirm these results, we also performed real-time qRT-PCR to detect the expression of these same transgenes, and this also showed that the 515Pgk2-CAT/ WT transgene was expressed in testis tissue whereas the 515Pgk2-CAT/CAAT-minus transgene was not (Fig. 1D).

\section{The CAAT box in the Pgk2 core promoter is not required for tissue-specific demethylation of DNA in the Pgk2 gene}

We used bisulfite genomic sequencing to determine whether the absence of an intact CAAT box would inhibit the demethylation process that normally occurs over the $5^{\prime}$-half of the Pgk2 gene prior to activation of Pgk2 transcription (Geyer et al. 2004). We previously showed that both the 515Pgk2-CAT/WT and 188Pgk2-CAT transgenes undergo tissue-, cell type-, and developmental stage-specific demethylation of DNA in early spermatogenic cells $\left(T_{1}-\right.$ and $T_{2}$-prospermatogonia and type A spermatogonia) in a manner analogous to that which the endogenous Pgk2 gene undergoes prior to initiation of transcription in spermatogenic cells in vivo (Ariel et al. 1994, Geyer et al. 2004). Importantly, both of those constructs carried an intact CAAT box. Here, we examined DNA methylation of the 515Pgk2-CAT/CAATminus transgene in testicular cells from the three different lines of mice carrying this transgene (Fig. 1F). While the 515Pgk2-CAT/CAAT-minus transgene in line \#20 showed only partial demethylation of the $5^{\prime}$-portion of the transgene, lines $\# 9$ and $\# 10$ showed demethylation to a similar extent as that seen in the 515Pgk2-CAT/WT transgene. Further, in each case, the observed demethylation event was testis specific as indicated by the hypermethylated status of both the 515Pgk2-CAT/WT and 515Pgk2-CAT/CAAT-minus transgenes in spleen tissue from the same mice in which methylation of the transgenes in germ cells was assessed (Fig. 1G). This indicates that the CAAT box alone is not the signal directing tissue-specific demethylation of the $P g k 2$ gene.

\section{Testis-specific reconfiguration of nucleosomes in the Pgk2 promoter accompanies active Pgk2 transcription}

Most genomic DNA in eukaryotes is incorporated into regularly, albeit randomly spaced nucleosomes to facilitate packaging and various processes associated with the DNA (Rando \& Chang 2009). However, regions of DNA closely associated with nucleosome core histones are typically inaccessible for binding by regulatory factors and/or the transcriptional preinitiation complex (Jenuwein \& Allis 2001). This conflict is normally resolved by reconfiguration of nucleosome presence and/or positioning relative to specific promoter sites required for protein-DNA interactions that facilitate activation of transcription (Cairns 2009). Thus, multiple studies have revealed differences in nucleosome positioning associated with the same gene in cells where the gene is actively expressed or terminally repressed respectively (Sekinger et al. 2005, Lam et al. 2008, Leimgruber et al. 2009). In addition, genome-level methodologies such as ChIP-Chip or ChIP-Seq have revealed tissue- or cell type-specific patterns of nucleosomal reconfiguration in multiple species including Saccharomyces cerevisiae (Yuan et al. 2005, Lee et al. 2007), Drosophila melanogaster (Mavrich et al. 2008), and Caenorhabditis elegans (Valouev et al. 2008), as well as in promoter (Ozsolak et al. 2007, Schones et al. 2008) and enhancer ( $\mathrm{He}$ et al. 2010) regions in the human genome. These studies reveal a characteristic pattern of nucleosome reconfiguration leading to unobstructed access facilitating binding of factors to enhancer, core promoter, and transcription start site regions in tissue-specific genes.

We examined nucleosome positioning at the Pgk2 gene promoter and enhancer region to determine whether similar tissue-specific differences in nucleosome positioning are associated with different transcriptional states of the Pgk2 gene. We isolated somatic spleen cells in which the Pgk2 gene is terminally repressed, and spermatogenic cells at stages prior to and during the time when the Pgk2 gene is actively transcribed, and used the MNase sensitivity assay to map nucleosome positioning in the $5^{\prime}$-flanking region of the Pgk2 gene in each cell type. Consistent with similar studies of other tissue-specific genes, we found that nucleosome positioning in the Pgk2 gene is distinctly different in non-expressing spleen cells and expressing spermatogenic cells. Thus, in spleen cells, we found occupancy at the -1 nucleosome position that includes the Pgk2 promoter/enhancer region plus the nearby transcription start site (Fig. 2B), while in a mixed population of pachytene spermatocytes and round spermatids in which the $P g k 2$ gene is actively expressed, the -1 nucleosome position was unoccupied (Fig. 2C). At the same time, the +1 nucleosome position remained occupied in both non-expressing spleen cells (Fig. 2B) and actively expressing germ cells (Fig. 2C), indicating a location-specific reconfiguration of nucleosomes in the Pgk2 5'-regulatory region.

To determine the timing of the reconfiguration of nucleosomes normally associated with activation of the $P g k 2$ gene in spermatogenic cells, we examined nucleosome positioning in the $5^{\prime}$ portion of the $P g k 2$ gene in premeiotic spermatogonia - a stage at which transcription of the Pgk2 gene has not yet begun (Gebara \& McCarrey 1992, McCarrey et al. 1992, 2005), and in pachytene spermatocytes and round spermatids - meiotic and postmeiotic spermatogenic cell types in which active expression of the Pgk2 gene is ongoing (McCarrey et al. 1992, 2005). We found that the -1 nucleosome position in the Pgk2 promoter was still occupied in premeiotic spermatogonia (Fig. 2D) but then became unoccupied in 
A
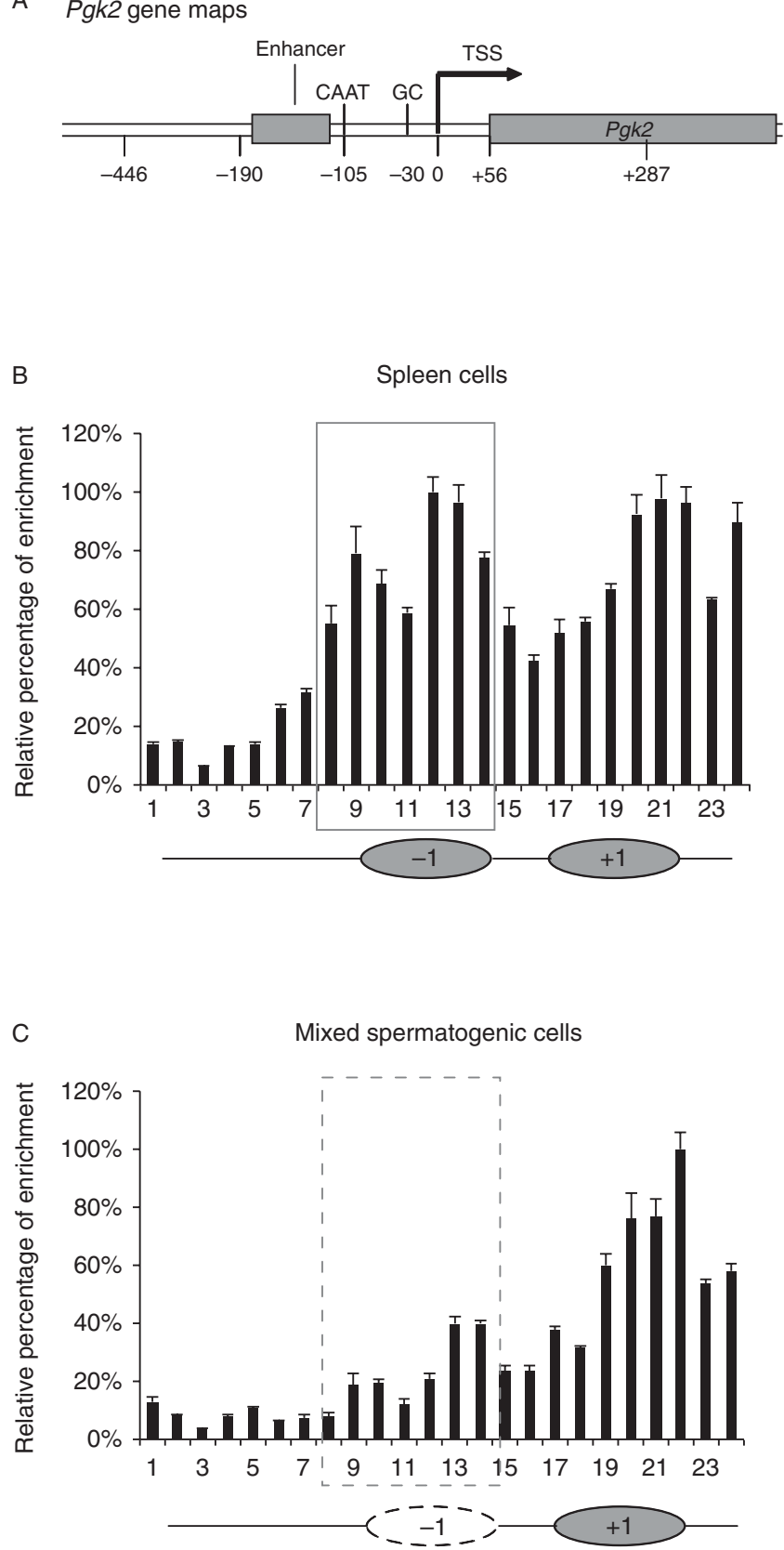

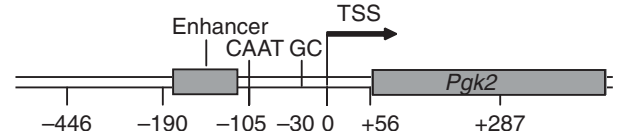

D

Primitive type A spermatogonia

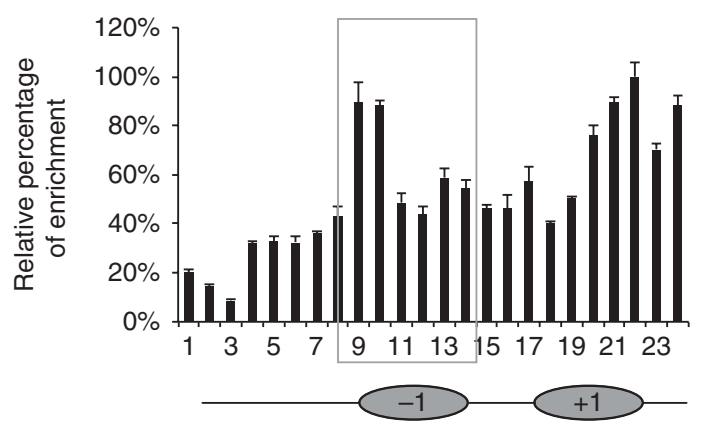

E

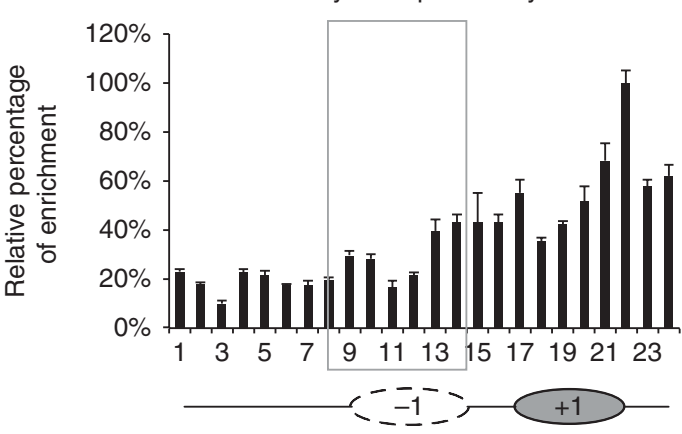

$\mathrm{F}$

Round spermatids

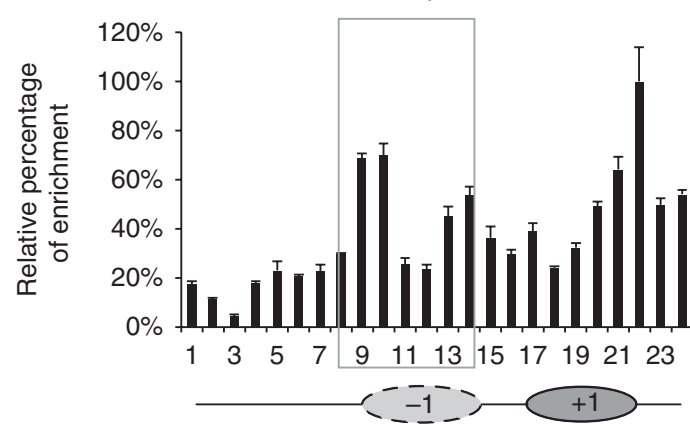

Figure 2 Nucleosome positioning in the endogenous Pgk2 gene in somatic and spermatogenic cells in the mouse. The MNase sensitivity assay was used to examine nucleosome positioning in the endogenous mouse Pgk2 gene in somatic cells in which the Pgk2 gene is terminally repressed, premeiotic spermatogonia in which the Pgk2 gene is undergoing potentiation prior to initiation of expression, and meiotic spermatocytes and postmeiotic spermatids in which the Pgk2 gene is actively expressed. Regions containing elevated amplimer levels represent the site of a nucleosome that inhibited access of the MNase to the underlying DNA, whereas regions of low amplimer levels represent more accessible sites devoid of nucleosomes. (A) Maps of the $5^{\prime}$ half of the Pgk2 gene provide context for each set of MNase assays. (B) Somatic spleen cells show the presence of nucleosomes (dark gray ovals) at the -1 region, which covers the Pgk2 enhancer and core promoter regions and at the +1 position within the Pgk2 coding sequence downstream of the transcription start site. (C) A mixed population of spermatogenic cells consisting primarily of Pgk2-expressing spermatocytes and spermatids shows the absence of a nucleosome at the -1 position in these cells (dashed oval), but the continued presence of a nucleosome at the +1 position. (D) A purified population of primitive type A spermatogonia in which the Pgk2 gene is not yet expressed shows the presence of nucleosomes at both the -1 and +1 positions, whereas in pachytene spermatocytes $(\mathrm{E})$, the -1 nucleosome is completely missing, and in round spermatids $(\mathrm{F})$, the -1 nucleosome presence is reduced (light gray dashed oval), while the +1 nucleosome persists in all these cell types. 
pachytene spermatocytes (Fig. 2E) and was still partially, although not as completely, unoccupied in round spermatids (Fig. 2F). Note that transcription of the Pgk2 gene ceases immediately after the round spermatid stage in elongating spermatids (McCarrey et al. 1992). Importantly, although we observed some variation among the different cell types investigated in the overall extent of post-MNase digestion signal intensity detected for each gene region, the differences were consistent within each gene region and were consistently distinct between those cell types in which the corresponding gene was or was not expressed. The post-MNase digestion signals do not reach 100 or $0 \%$ in any case because i) the purities of the enriched cell populations investigated were $85-95 \%$ and ii) reconfiguration of nucleosomes on any promoter is likely to reflect an equilibrium state that never reaches 100 or $0 \%$ simultaneously in all cells examined, even within a particular cell type.

\section{The CAAT box is required for reconfiguration of nucleosomes in the Pgk2 promoter}

The tissue- and location-specific reconfiguration of nucleosomes at the -1 position in the $5^{\prime}$-region of the Pgk2 gene implies a highly regulated process. Because we had previously observed an in vivo footprint over the CAAT box in spermatogenic cells before but not during the time of active transcription of the $P g k 2$ gene, we next examined the extent to which normal nucleosome reconfiguration occurred in 515Pgk2-CAT transgenes lacking an intact CAAT box (i.e., in 515Pgk2-CAT/ CAAT-minus transgenes). We first confirmed that the 515Pgk2-CAT/WT transgene carrying an intact CAAT box undergoes a tissue-specific reconfiguration of nucleosomes at the -1 position in a manner similar to that we observed in the endogenous Pgk2 gene (Fig. 3A). Interestingly, in addition to nucleosome occupancy at the -1 position in this transgene, we also observed occupancy at a site upstream from the -1 position in both spleen and germ cells that we termed the -2 position (Fig. 3A). This was not observed in the endogenous Pgk2 gene, presumably because the sequence differs in the regions upstream of the endogenous $P g k 2$ gene and any integrated Pgk2 transgenes respectively. We also did not observe consistent nucleosome occupancy at the +1 position in these transgenes, which we suspect also reflects sequence differences between the transgenes (carrying the CAT reporter gene downstream of the Pgk2 promoter) and the endogenous Pgk2 gene. However, the key observation was that when nucleosome mapping was performed on the $5^{\prime}$-portion of the 515Pgk2-CAT/WT transgene in non-expressing spleen cells and in expressing spermatocytes or spermatids, respectively, only occupancy at the -1 position changed, becoming unoccupied in expressing germ cells consistent with the result we observed for the endogenous Pgk2 gene.
We next examined nucleosome positioning in the 515Pgk2-CAT/CAAT-minus transgenes in these same cell types. In all three lines carrying the CAAT-minus transgene, there was no difference in nucleosome occupancy in spleen and germ cells respectively (Fig. 3B), such that the -1 position remained occupied even in spermatogenic cell types in which the equivalent position in the endogenous Pgk2 gene or in the 515Pgk2CAT/WT transgene became unoccupied. This correlated with the lack of expression of this transgene in testis tissue from any of these lines described earlier. Thus, it appears that an intact CAAT box is required for both reconfiguration of nucleosomes over the $P g k 2$ promoter and tissue-specific initiation of transcription from this promoter.

\section{Testis-specific modifications of histones accompany activation of Pgk2 transcription}

A common molecular event that accompanies physical remodeling of chromatin and activation of tissue-specific transcription is modification of core histones (Jenuwein \& Allis 2001). Both histone tails and globular domains are subject to a vast array of posttranslational modifications sometimes referred to as the histone code (Berger 2002, Barth \& Imhof 2010). These modifications include acetylation, methylation, ubiquitination, ADP-ribosylation, and sumoylation of lysine residues, methylation of arginine residues, and other modifications (Kouzarides 2007). Commonly, acetylation of histone H3 and histone $\mathrm{H} 4$ (acetyl-H3 and acetyl-H4), and tri-methylation of lysine 4 of histone $\mathrm{H} 3$ ( $\mathrm{H} 3 \mathrm{k} 4 \mathrm{me} 3)$, is associated with a euchromatic chromatin structure and active transcription. Therefore, we used the ChIPassay to investigate these three modifications in different regions of the $P g k 2$ gene in somatic spleen cells in which the Pgk2 gene is terminally repressed, premeiotic spermatogonia in which the Pgk2 gene is not yet expressed, and spermatocytes and spermatids in which the Pgk2 gene is actively expressed (Fig. 4). We also investigated similar modifications in two control genes in the same cell populations the $\beta$-actin gene that is constitutively expressed in spermatogenic and spleen cells and the Cryaa gene, which is terminally repressed in these same cell types.

All three modifications were elevated in the $\beta$-actin gene relative to the Cryaa gene in both somatic spleen cells and pachytene spermatocytes, confirming the association of these modifications with actively transcribed genes (Fig. 4B). Similarly, these modifications were generally low in the Pgk2 gene in spleen cells and in premeiotic spermatogonia, similar to levels seen for the repressed Cryaa gene in both somatic and germ cells. However, beginning in primary spermatocytes in which active transcription of the $P g k 2$ gene is initiated (McCarrey et al. 1992), we observed a gradual increase in all three modifications that reached a peak in either pachytene spermatocytes or round spermatids (Fig. 4B) 
A

515Pgk2-CAT/WT
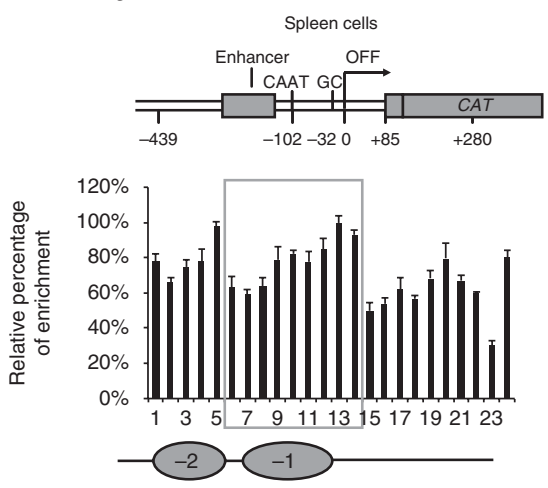

B

515Pgk2-CAT/CAAT-minus
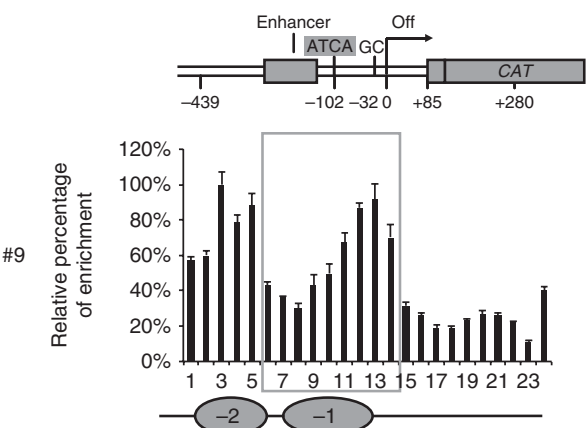

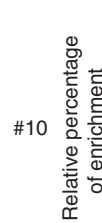
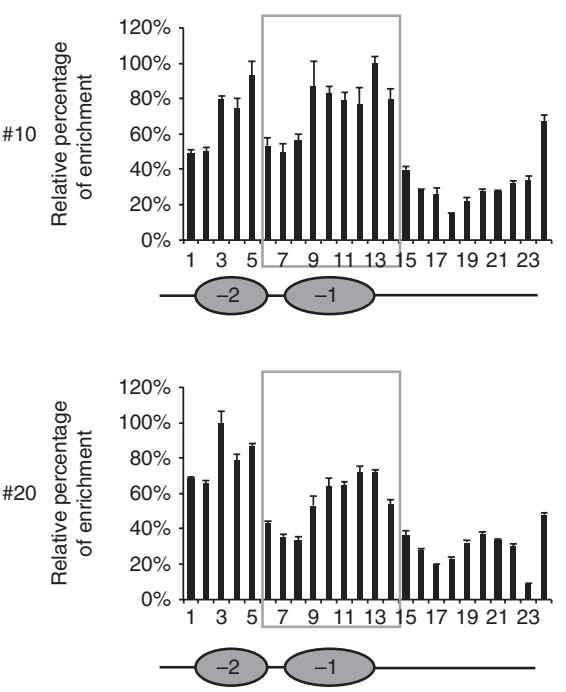
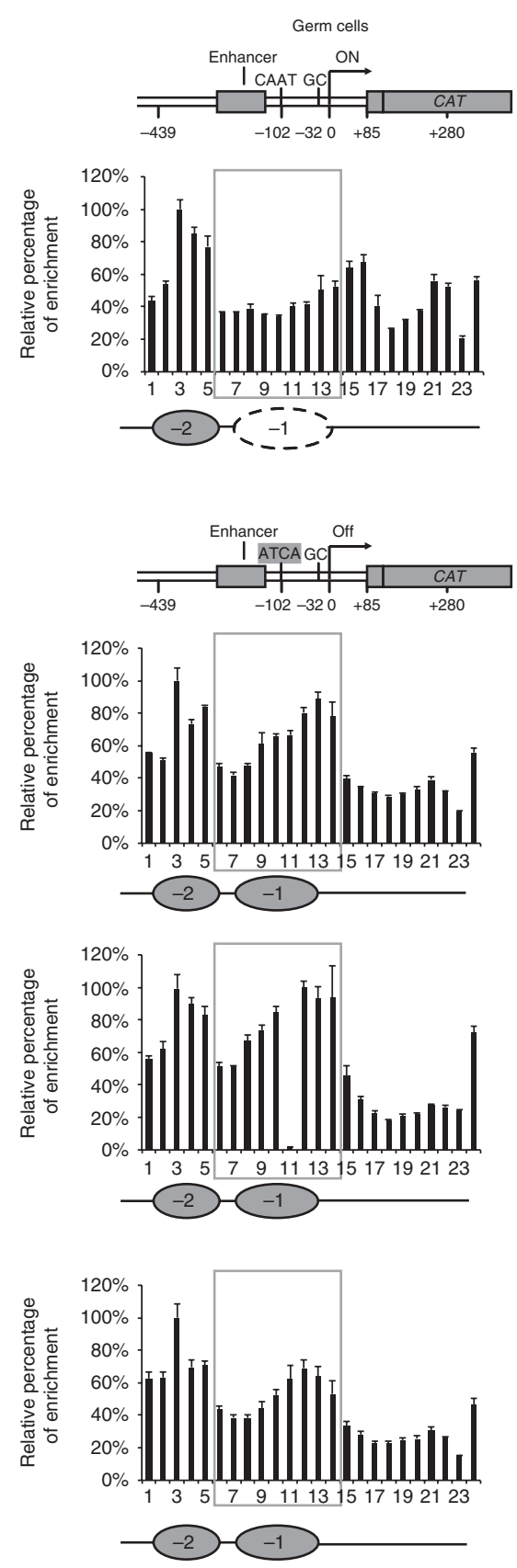

Figure 3 Nucleosome positioning in Pgk2 transgenes with or without intact CAAT boxes. (A) The MNase sensitivity assay was used to examine nucleosome positioning in the 515Pgk2-CAT/WT transgene in spleen cells and in a mixed population of male germ cells (pachytene spermatocytes and round spermatids). A nucleosome (gray oval) was present at the -1 position over the Pgk2 enhancer and core promoter regions in non-expressing spleen cells but was absent from this position in expressing germ cells. An additional nucleosome was persistently present further upstream in what has been termed the -2 position, but no persistent nucleosome was detected at the +1 position in these transgenes. Note that the DNA sequence in the -2 and +1 regions of these transgenes differs from that in the equivalent positions of the endogenous $P g k 2$ gene. (B) The nucleosome at the -1 position persisted in the 515Pgk2-CAT/ CAAT-minus transgene in both spleen cells and male germ cells in all three lines investigated. in a pattern that directly mimicked the gradual increase in expression levels of this gene in the same cell types (McCarrey et al. 1992, Yoshioka et al. 2007). Levels of all three modifications associated with the Pgk2 gene in pachytene spermatocytes and round spermatids were similar to those seen for the same modifications in the constitutively expressed $\beta$-actin gene, indicating that these modifications are associated with a state of active expression of the $P g k 2$ gene. The gradually increasing pattern of these modifications in progressively later spermatogenic cell types was similar for all three modifications investigated (Fig. 4B) and correlates with previously published results describing ongoing transcription of the Pgk2 gene in primary spermatocytes and round spermatids (Kumari et al. 1996). In addition, the increase in these modifications was seen in both the promoter and coding regions of the $P g k 2$ gene, with the increase being greatest in the coding region.

\section{The Pgk2 enhancer region plus the CAAT box are required to direct activating histone modifications}

As with reconfiguration of nucleosomes, the tissue specificity and developmental stage specificity of these 
A
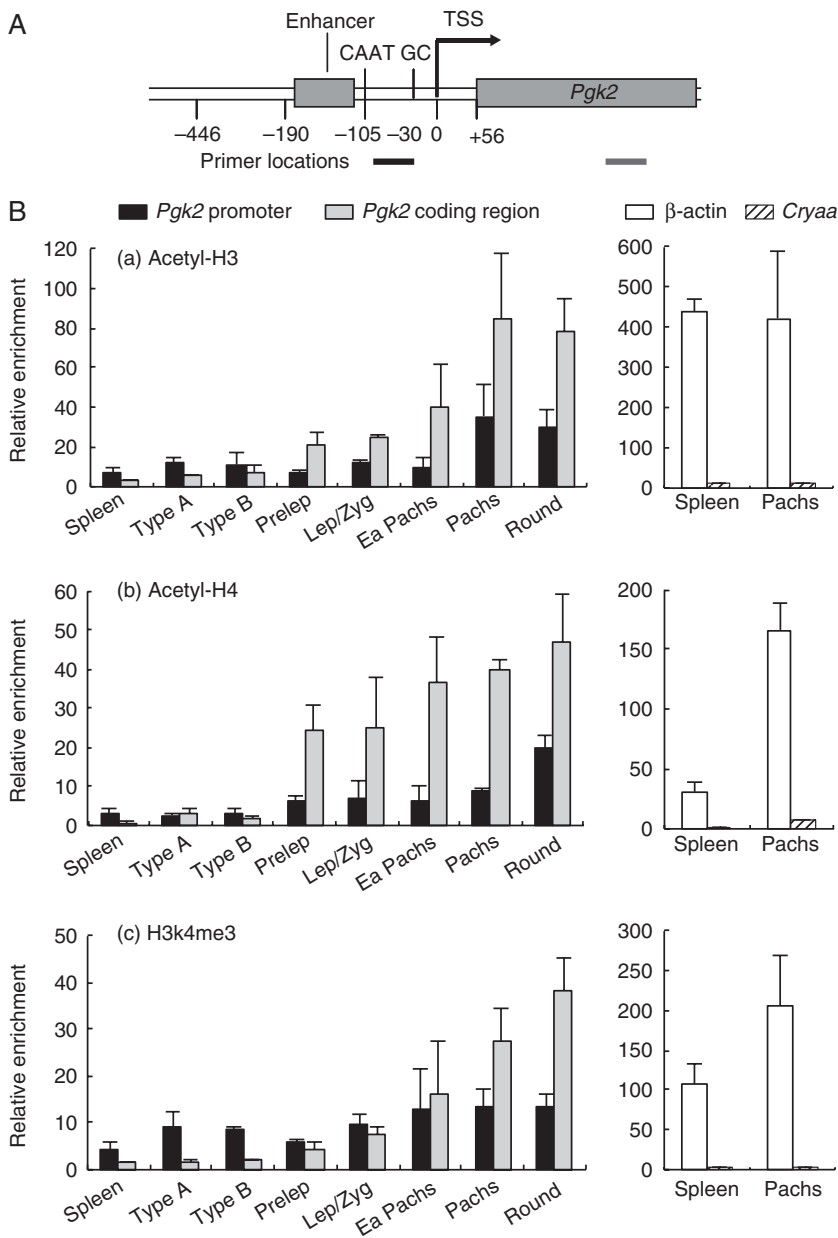

Figure $4 \mathrm{ChIP}$ analysis of activating histone modifications in the endogenous Pgk2 gene. (A) A map of the intronless Pgk2 gene showing the positions of amplicons analyzed for histone modifications by ChIP. One amplicon (filled black bars in the graphs) was located within the $P g k 2$ promoter and a second amplicon (open bars in the graphs) was located in the Pgk2 coding sequence. (B) ChIP analysis of three different activating histone modifications, (a) acetyl-H3, (b) acetyl-H4, and (c) $\mathrm{H} 3 \mathrm{k} 4 \mathrm{me}$, in the Pgk2 gene in different cell types, and in two control genes ( $\beta$-actin or Cryaa) in spleen cells (Spleen) and pachytene spermatocytes (Pachs). The $\beta$-actin gene is ubiquitously active in all cell types and showed consistent enrichment for all three activating histone modifications in both spleen cells and spermatocytes, while the Cryaa gene is repressed in both spleen cells and spermatocytes and showed an absence of activating histone modifications in both cell types. The Pgk2 gene also showed an absence of activating histone modifications in spleen cells where this gene is terminally repressed, and in premeiotic type A and type B spermatogonial cells in which the Pgk2 gene has not yet undergone initiation of transcription. However, all three activating histone modifications showed enrichment in the Pgk2 gene in cells actively expressing this gene, including successive types of primary spermatocytes - preleptotene spermatocytes (Prelep), leptotene plus zygotene spermatocytes (Lep/Zyg), early pachytene spermatocytes (Ea Pachs), and fully mature pachytene spermatocytes (Pachs), as well as in round spermatids (Round). Enrichment for these histone modifications was generally greater in the Pgk2 coding sequence than in the Pgk2 promoter in cells actively expressing this gene. histone modifications suggest a highly regulated process on a gene-specific level. To determine which part of the $P g k 2$ gene signals these modifications, we examined transgenes carrying the WT Pgk2 core promoter alone ( = the 188Pgk2-CAT transgene) or the WT Pgk2 core promoter plus enhancer regions $(=$ the 515Pgk2CAT/WT transgene), as well as the transgene carrying the Pgk2 enhancer plus core promoter regions but with a mutated CAAT box ( $=$ the 515Pgk2-CAT/CAAT-minus transgene) (Fig. 5). The intact 515Pgk2-CAT/WT transgene showed germ cell-specific enrichments of acetyl$\mathrm{H} 3$ and acetyl-H4 (especially in spermatocytes and spermatids) that were diminished in the $188 \mathrm{Pgk} 2$-CAT transgene (Fig. 5B). This indicated that at least part of the signal that directs tissue-specific acquisition of acetylation of histones $\mathrm{H} 3$ and $\mathrm{H} 4$ in the Pgk2 promoter appears to reside in the upstream enhancer region. However, the 515Pgk2-CAT/CAAT-minus transgene also failed to acquire tissue-specific acetylation of $\mathrm{H} 3$ and $\mathrm{H} 4$, suggesting that the complete gene-specific signal that directs this modification may extend from the Pgk2 enhancer region through the $5^{\prime}$-portion of the Pgk2 core promoter where the CAAT box resides.

\section{Summary of Pgk2 promoter regions required to signal each molecular event associated with transcriptional activation of the Pgk2 gene}

Table 1 summarizes the occurrence of four different molecular events in the presence of different regions of the Pgk2 promoter+enhancer regions in transgenes. Thus, from a transgene carrying an intact Pgk2 enhancer plus core promoter region, transcription is initiated with normal tissue specificity and developmental stage specificity (Robinson et al. 1989, Zhang et al. 1999). However, in the absence of the enhancer region, or of an intact CAAT box in the core promoter region even when the enhancer region is present, transcription is not initiated from this promoter. Acquisition of activating histone modifications (acetyl $\mathrm{H} 3$, acetyl $\mathrm{H} 4$, and $\mathrm{H} 3 \mathrm{k} 4 \mathrm{me} 3$ ) requires an intact CAAT box in the $P g k 2$ core promoter along with the presence of the Pgk2 enhancer region. Reconfiguration of nucleosomes also requires an intact CAAT box in the core promoter. Whether or not the Pgk2 enhancer region is required for nucleosome reconfiguration could not be determined because the 188Pgk2-CAT transgene that lacks the enhancer region also lacks a significant portion of the upstream sequence that normally makes up the -1 nucleosome position. Finally, the signal for cell typeand developmental stage-specific demethylation of DNA in the $5^{\prime}$ half of the $P g k 2$ gene appears to reside in the $P g k 2$ core promoter and does not require the presence of the enhancer region. However, an intact CAAT box in the core promoter does not appear to be a specific requirement for this signaling function. 
A

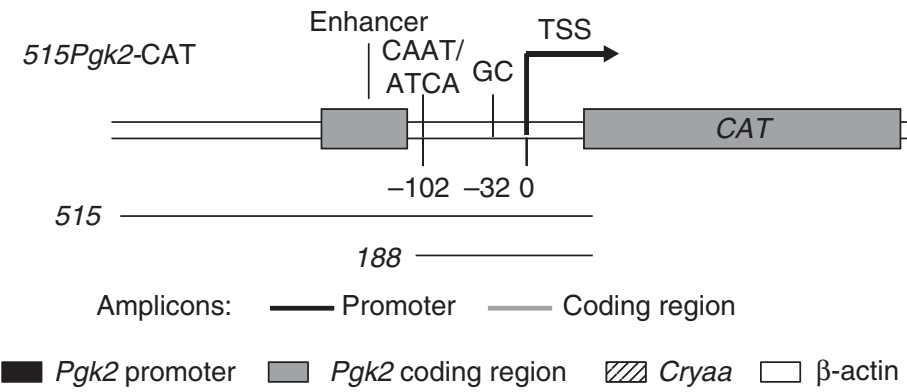

B
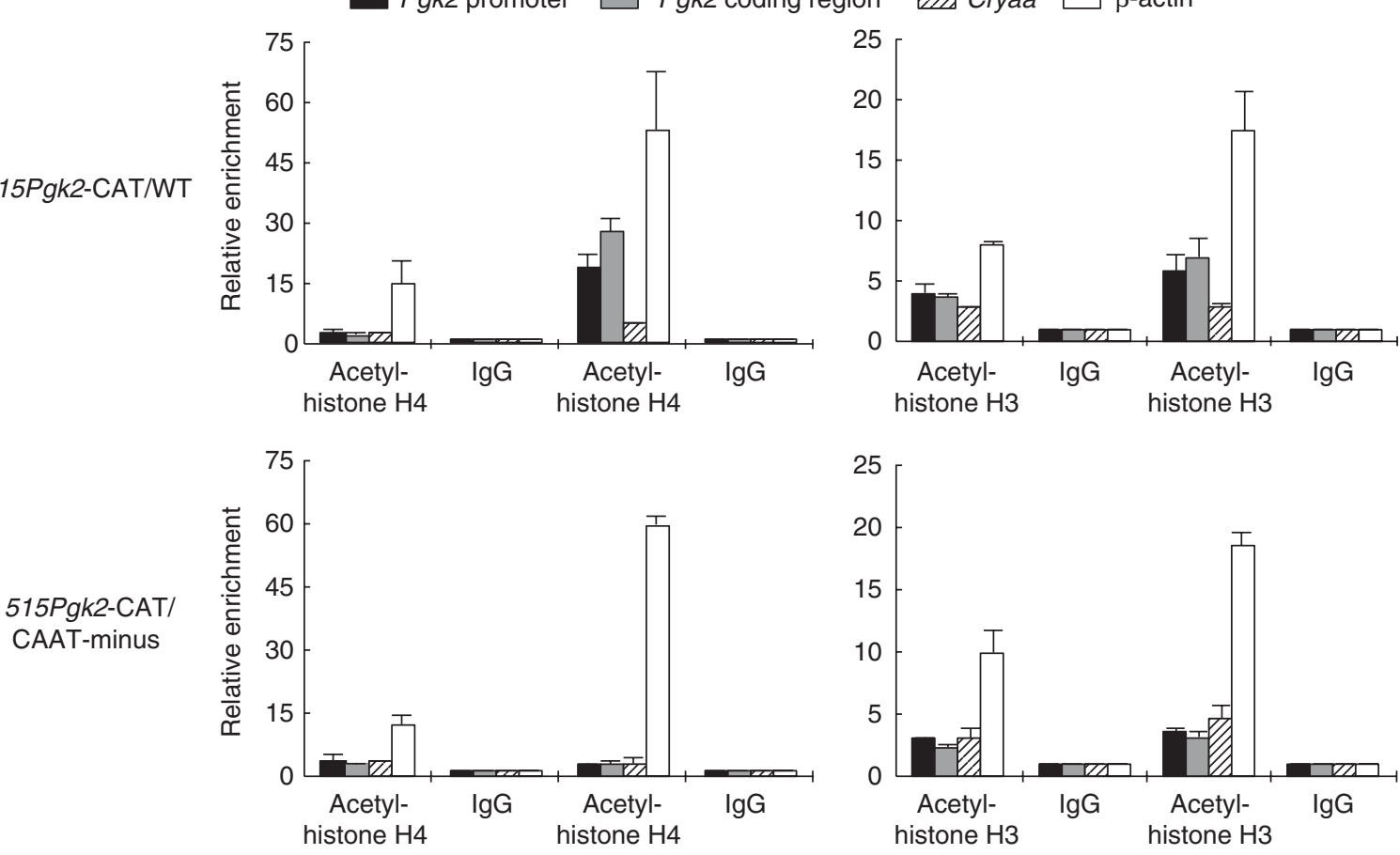

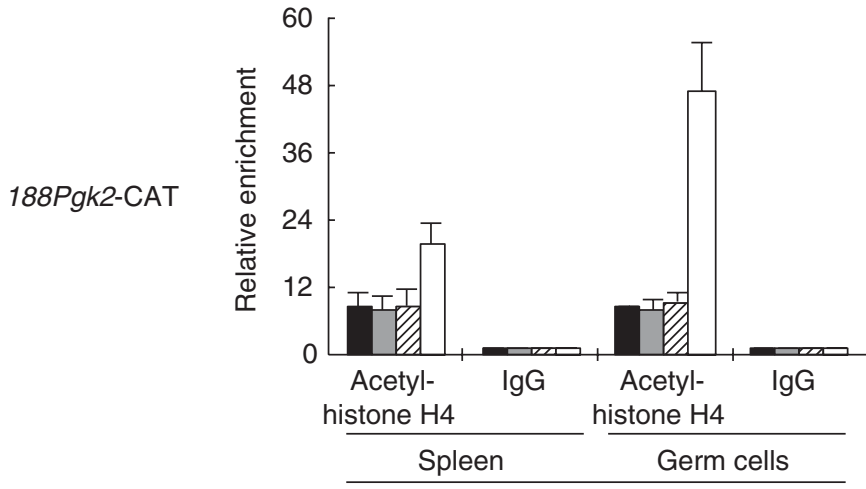

Acetylated-histone $\mathrm{H} 4$

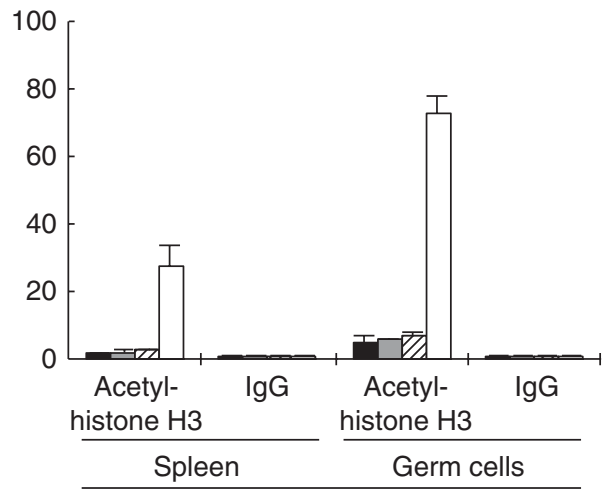

Acetylated-histone $\mathrm{H} 3$

Figure 5 ChIP analysis of histone acetylation in Pgk2 transgenes. (A) A map of the Pgk2-CAT transgenes shows the position of amplicons analyzed for acetyl-H3 or acetyl-H4 in Pgk2-CAT transgenes. (B) Relative enrichment of acetylated $\mathrm{H} 4$ (graphs on the left) or acetylated $\mathrm{H} 3$ (graphs on the right) is shown for each transgene as well as for the two control genes, $\beta$-actin and Cryaa in spleen cells or mixed male germ (spermatogenic) cells. The 515Pgk2-CAT/WT transgene, which is actively expressed in spermatogenic cells, shows significant enrichment for both acetyl-H3 and acetyl-H4 in male germ cells but not in spleen cells where this transgene is not expressed. The 515Pgk2-CAT/CAAT-minus transgene, which contains all regulatory sequences normally required to direct testis-specific expression except for an intact CAAT box in the core promoter, and which is not expressed in either spleen cells or spermatogenic cells, shows no enrichment of acetyl-H3 or acetyl-H4 in either cell type. Similarly, the 188Pgk2-CAT transgene, which contains only the Pgk2 core promoter and no enhancer region and is not expressed in either spleen or spermatogenic cells, shows no enrichment for either histone modification in either cell type. 
Table 1 Regulation of molecular events associated with transcriptional activation of the $P g k 2$ gene.

\begin{tabular}{|c|c|c|c|}
\hline \multirow[b]{2}{*}{ Molecular event } & \multicolumn{3}{|c|}{ Specific Pgk2 promoter regions } \\
\hline & $\begin{array}{c}\text { Intact } \\
\text { enhancer }+ \\
\text { intact core } \\
\text { promoter }\end{array}$ & $\begin{array}{l}\text { Intact } \\
\text { core } \\
\text { promoter } \\
\text { only }\end{array}$ & $\begin{array}{c}\text { Intact } \\
\text { enhancer }+ \\
\text { core promoter } \\
\text { lacking CAAT }\end{array}$ \\
\hline Demethylation of DNA & + & + & + \\
\hline Nucleosome reconfiguration & + & $N A^{a}$ & - \\
\hline Histone modifications & + & - & - \\
\hline Initiation of transcription & + & - & - \\
\hline
\end{tabular}

a Note that in the absence of the enhancer region, the sequence over which the -1 position at which a nucleosome is normally found in non-expressing cells is missing.

\section{Discussion}

Spermatogenesis is a highly dynamic process of cellular differentiation that has been correlated with a highly dynamic series of changes in gene expression (Almstrup et al. 2004, Shima et al. 2004, Roy Choudhury et al. 2010). These changes include the activation of numerous testis-specific genes including several tissue-specific members of gene families that encode testis-specific isozymes (McCarrey \& Thomas 1987, Mori et al. 1993, Boussouar \& Benahmed 2004, Tang et al. 2008). One example is the testis-specific Pgk2 gene, transcriptional activation of which occurs in primary spermatocytes coincident with the onset of meiotic prophase. Interestingly, this is also the time at which the X-linked Pgk1 gene, which encodes the form of the glycolytic enzyme phosphoglycerate kinase (PGK-A) that is expressed in all somatic or germ cell types carrying at least one transcriptionally active $X$ chromosome, undergoes silencing due to the process of meiotic sex chromosome inactivation (MSCl; McCarrey \& Thomas 1987, McCarrey et al. 1992, Wang et al. 2005, Turner 2007). Thus, meiotic and postmeiotic spermatogenic cells are unique in the absence of at least one active $\mathrm{X}$ chromosome, and this presents a dilemma because these cells, especially spermatozoa, require PGK to carry out glycolysis. It appears that a gene duplication event that occurred early during mammalian evolution has solved this dilemma in mammals by providing an autosomal copy of the Pgk gene (Pgk2), which encodes a testis-specific isozyme of PGK-A (PGK-B) that is not subject to $\mathrm{MSCl}$, and that undergoes tissue-specific transcriptional activation at the same time that the Pgk1 gene becomes silenced, such that a source of PGK protein is maintained throughout spermatogenesis (McCarrey et al. 1992, 1996).

Because the development and differentiation of the male germ line in mammals has been well characterized, and because many of the different cell types that make up this lineage can be recovered in relatively pure populations, spermatogenesis provides an excellent opportunity to study the developmental process of transcriptional activation of tissue-specific genes
(Bellve 1993, McCarrey 1998). This has allowed us to chronicle molecular events that are associated with transcriptional activation of the spermatogenesisspecific Pgk2 gene (McCarrey et al. 1992, 1996, Geyer et al. 2004, Yoshioka et al. 2007). We previously showed that activation of the Pgk2 gene is associated with binding of ubiquitous transcription factors to the Pgk2 core promoter (Gebara \& McCarrey 1992, Berg et al. 1993, Yoshioka et al. 2007) and testis-specific factors to the Pgk2 enhancer region (Robinson et al. 1989, Gebara \& McCarrey 1992, Yoshioka et al. 2007). We also showed that there is a general increase in nuclease (DNase I) sensitivity over the entire Pgk2 gene (Kramer et al. 1998), as well as the development of a DNase I hypersensitive site at the Pgk2 promoter (Kumari et al. 1996) in cells that express this gene. Finally, we showed that activation of the Pgk2 gene is preceded by demethylation of DNA over the 5'-portion of the gene (Ariel et al. 1994, Zhang et al. 1998, Geyer et al. 2004).

In the study described here, we have shown that two additional molecular events associated with chromatin remodeling - reconfiguration of nucleosomes and acquisition of activating histone modifications - also occur during the process of transcriptional activation of the $P g k 2$ gene. Thus, a nucleosome at the -1 position that corresponds to a region spanning the enhancer and core promoter region of the $P g k 2$ gene is present in nonexpressing cells but is absent in cells in which the Pgk2 gene is actively transcribed. Interestingly, an adjacent nucleosome at the +1 position in the $5^{\prime}$ portion of the coding sequence remains present in both expressing and non-expressing cell types. This indicates that reconfiguration and/or displacement of the nucleosome at the -1 position is specifically correlated with events ongoing in the promoter region of the Pgk2 gene associated with transcriptional activation of this gene.

The acquisition of histone modifications including acetyl $\mathrm{H} 3$, acetyl $\mathrm{H} 4$, and $\mathrm{H} 3 \mathrm{k} 4 \mathrm{me} 3$ also shows a direct correlation with active expression of this gene. However, these modifications occur in both the Pgk2 promoter and coding sequence regions. Indeed, these modifications are most pronounced in the Pgk2 coding sequence in expressing cell types. This likely reflects the fact that nucleosome reconfiguration significantly reduces the overall representation of histones in the Pgk2 promoter region and that these histone modifications facilitate the elongation as well as initiation phases of transcription (Berger 2002). Acetylation of lysine residues is known to contribute to changes in nucleosome/chromatin structure that facilitate recruitment of other transcription factors to promoter regions and/or more efficient processivity of RNA polymerase during the elongation phase of transcription (Brownell et al. 1996, Marmorstein \& Roth 2001, Allis et al. 2007, Marmorstein \& Trievel 2009). Our findings that reconfiguration of nucleosomes and modifications of histones accompany activation of transcription of the Pgk2 gene are consistent with those 
previously reported for several other genes (Kouskouti \& Talianidis 2005, Villagra et al. 2006, Plachetka et al. 2008) and are therefore not novel in that respect. However, our results do provide novel information regarding the order of these and other molecular events involved in transcriptional activation of the Pgk2 gene in particular and of tissue-specific genes in general.

Thus, based on the data presented here, as well as those from our previously published studies including bisulfite sequencing analysis of demethylation of the $P g k 2$ gene (Zhang et al. 1998, Geyer et al. 2004), in vivo footprinting of the Pgk2 5'-regulatory region (Yoshioka et al. 2007), general nuclease sensitivity studies (Kramer et al. 1998), analysis of DNase I hypersensitive site formation (Kumari et al. 1996), and ChIP assays to detect binding of specific factors to the Pgk2 enhancer and core promoter regions in vivo (Yoshioka et al. 2007), we can now propose a developmental order of molecular regulatory events involved in activation of transcription of the $P g k 2$ gene (Fig. 6). These include two events that clearly precede initiation of transcription of the Pgk2 gene - step 1) demethylation of DNA in the $5^{\prime}$ half of the Pgk2 gene beginning in $\mathrm{T}_{1}$-prospermatogonia at 18 days postcoitum (dpc) and completed by the primitive type A spermatogonial stage at $6 \mathrm{dpp}$, and step 2) binding of one or more factors (possibly CCAAT/enhancer binding protein $(\mathrm{C} / \mathrm{EBP} \beta)$, see below) to a region in the Pgk2 core promoter that extends from the CAAT box to just upstream of the GC box in premeiotic spermatogonia (Geyer et al. 2004), plus recruitment of chromatin remodeling factors or complexes in early primary spermatocytes. These events are followed by a series of events that occur just prior to, or coincident with initiation of Pgk2 transcription in primary spermatocytes, beginning with step 3 ) reconfiguration of the -1 nucleosome covering the Pgk2 core promoter and enhancer regions as shown in this study, formation of a DNase I hypersensitive site as shown in a previous study (Kumari et al. 1996), binding of testis-specific factors (PBX4 and PREP1) to the E3/E4 portion of the Pgk2 enhancer region, and Sp3 to the GC box in the Pgk2 core promoter as shown in another previous study (Yoshioka et al. 2007), changes in histone modifications as shown in this study, and an increase in general nuclease sensitivity throughout the $P g k 2$ locus as shown in yet another previous study (Kramer et al. 1998). Finally, step 4) formation of a complete preinitiation complex is completed by recruitment of general transcription factors plus RNA polymerase II and transcription is initiated. This scheme is depicted in Fig. 6.

In this study, we have also shown that an intact CAAT box is required for both the acquisition of activating histone modifications and nucleosome reconfiguration. The CAAT box is an element found in the core promoters or enhancers of many ubiquitously expressed and tissuespecific genes (Mantovani 1999, Villagra et al. 2006, Plachetka et al. 2008). It is known to serve as a binding site for multiple ubiquitous transcription factors including

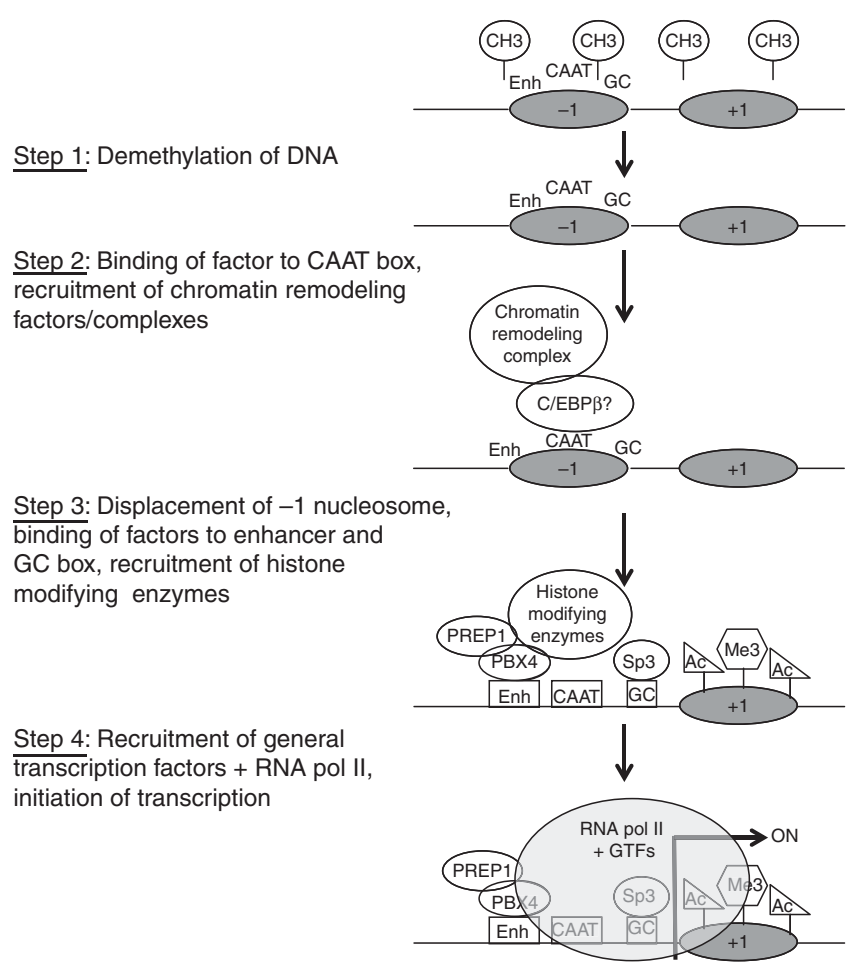

Figure 6 Model of events leading up to transcriptional activation of the $P g k 2$ gene during spermatogenesis. A series of molecular events involved in transcriptional activation of the $P g k 2$ gene during spermatogenesis is proposed based on observations reported in this and previous studies. Where possible, these events are shown in developmental chronological order and include Step 1 - demethylation of DNA in the $5^{\prime}$-half of the $P g k 2$ gene, which begins in

$\mathrm{T}_{1}$-prospermatogonia and is completed by the primitive type $\mathrm{A}$ spermatogonia stage; Step 2 - binding of one or more factors (possibly $\mathrm{C} / \mathrm{EBP} \beta$ ) to the CAAT box and surrounding sequences in the Pgk2 core promoter to attract a chromatin remodeling complex; Step 3 - displacement of the nucleosome at the -1 position, binding of factors to the enhancer and core promoter regions, and recruitment of histone-modifying enzymes; and Step 4 - formation of the complete preinitiation complex including recruitment of RNA polymerase II and initiation of transcription. $\mathrm{CH} 3$, methyl groups on $\mathrm{CpG}$ dinucleotides; Enh, enhancer region; CAAT, CAAT box; GC, GC box; Ac, histone acetylation; Me3, histone tri-methylation.

CCAAT transcription factor/nuclear factor 1 (Nagata et al. 1982, Santoro et al. 1988), C/EBP (Chang et al. 1990, Roman et al. 1990), and nuclear factor Y/Hem activation protein (Li et al. 1992, McNabb et al. 1995), among others (Nepveu 2001). Thus, while it is not surprising to find that the CAAT box in the $P g k 2$ promoter is important for initiation of transcription, we were surprised to observe in our ChIP studies of protein-DNA interactions associated with the Pgk2 gene in spermatocytes or spermatids (Yoshioka et al. 2007) that none of the common ubiquitous factors known to bind to CAAT boxes appear to be bound to this sequence in the actively expressed Pgk2 gene. This was confirmed by our in vivo footprinting studies (Yoshioka et al. 2007) that showed this site remains unoccupied in these same cells. Interestingly, we did observe in vivo footprints over the 
CAAT box and nearby regions of the Pgk2 core promoter during the spermatogonial stage, prior to initiation of $P g k 2$ transcription in primary spermatocytes. This has led us to speculate that an intact CAAT box is required for chromatin remodeling events that immediately precede initiation of $P g k 2$ transcription. Specifically, we suggested that the CAAT box and nearby sequences serve as signals to direct chromatin remodeling by binding factors or chromatin remodeling complexes in a gene-, cell type-, and developmental stage-specific manner. Our observation that these events fail to occur in a transgene lacking an intact CAAT box but possessing all other regulatory regions normally required for tissue-specific activation of transcription from the $P g k 2$ promoter suggests that the CAAT box does indeed play a role in signaling chromatin remodeling, which is, in turn, a mandatory prerequisite for subsequent molecular events required for transcription from the $P g k 2$ promoter, including binding of some or all of the transcription factors that are normally required for initiation of $P g k 2$ transcription.

There have been previous reports of factors binding to CAAT boxes to initiate chromatin remodeling in conjunction with tissue-specific activation of transcription. Tissue-specific activation of the bone-specific $O C$ gene requires chromatin remodeling by the SWI/SNF complex recruited to the proximal promoter by $\mathrm{C} / \mathrm{EBP} \beta$, which binds to a CAAT box-like sequence (Villagra et al. 2006). Similarly, C/EBP $\beta$ has been shown to bind to an upstream enhancer site in the tissue-specific chicken mim-1 gene to induce decondensation of chromatin prior to activation of transcription (Plachetka et al. 2008). Both these studies showed that the C/EBP $\beta$ factor is required for chromatin remodeling associated with, and required for, activation of tissue-specific transcription. Our study shows that an intact CAAT box is specifically required for this process in the testis-specific Pgk2 gene and suggests this element may function by recruiting C/EBP $\beta$ and chromatin remodeling complexes to promote acquisition of activating histone modifications, decondensation of chromatin, and reconfiguration of nucleosomes, although we have yet to directly demonstrate this.

A Pgk2 transgene lacking an intact CAAT box but possessing all other $5^{\prime}$-regulatory sequences normally required for tissue-specific activation of Pgk2 transcription failed to acquire activating histone modifications or initiate transcription, indicating that chromatin remodeling directed by the Pgk2 CAAT box is a mandatory prerequisite for activation of transcription from the $P g k 2$ promoter. Our observation of in vivo footprints over the CAAT box and nearby regions in spermatogonia, but not in spermatocytes or spermatids (Yoshioka et al. 2007), indicates that these chromatin remodeling steps normally occur prior to the initiation of transcription and do not need to be continually reinforced during active transcription. Thus, the model we propose in Fig. 6 suggests that a single chromatin remodeling event is required to facilitate access for most or all of the transcription factors that regulate ongoing expression of the $P g k 2$ gene to bind to their cognate sites in the $P g k 2$ core promoter and enhancer regions. We further observed that a transgene carrying the Pgk2 core promoter but not the upstream enhancer region failed to undergo activating histone modifications, suggesting that the enhancer region is also required to direct acquisition of these modifications.

We previously showed that the PBX4 transcription factor and its co-activator, PREP1, become bound to the Pgk2 E3/E4 enhancer region beginning in primary spermatocytes (Yoshioka et al. 2007), which is the same time at which we now show activating histone modifications appear. A previous report showed that the PBX4 factor can interact with histone lysine acetyltransferases to direct acetylation of chromatin (Choe et al. 2009). Taken together, our results are consistent with a model in which the CAAT box in the Pgk2 core promoter is required to direct chromatin remodeling (potentially through binding of $C / E B P \beta$ ), and the $E 3 / E 4$ enhancer region is required to direct acquisition of activating histone modifications through binding of the PBX4 activator and its co-activator, PREP1. Because a transgene carrying an intact Pgk2 enhancer region but a disrupted CAAT box failed to undergo the histone modifications normally associated with transcriptional activation, we would further suggest that the chromatin remodeling step directed by the CAAT box is a prerequisite for the histone modification step directed by the enhancer region in the Pgk2 gene.

Our previous studies have also shown that demethylation of DNA in the $5^{\prime}$ half of the Pgk2 gene precedes the chromatin remodeling events, as well as binding of transcription factors to the $P g k 2$ promoter and initiation of transcription. We previously showed that the Pgk2 enhancer region is not required to direct demethylation of the Pgk2 gene (Zhang et al. 1998, Geyer et al. 2004), and in this study, we showed that an intact CAAT box is also not required for this demethylation event. Thus, tissue-specific demethylation appears to be regulated independently from chromatin remodeling and activating histone modifications in the Pgk2 gene. How the demethylation step is signaled in a gene-, cell type-, and developmental stage-specific manner and whether or not that event is a mandatory prerequisite for the subsequent molecular events associated with activation of the Pgk2 transcription remain to be determined.

\section{Supplementary data}

This is linked to the online version of the paper at http://dx. doi.org/10.1530/REP-13-0311.

\section{Declaration of interest}

The authors declare that there is no conflict of interest that could be perceived as prejudicing the impartiality of the research reported. 


\section{Funding}

This work was supported by NIH grant RO1 HD46637 to J R McCarrey.

\section{Acknowledgements}

The authors thank Jacey Hornecker for technical assistance with preparations of purified spermatogenic cell types.

\section{References}

Allis CD, Berger SL, Cote J, Dent S, Jenuwien T, Kouzarides T, Pillus L, Reinberg D, Shi Y, Shiekhattar R et al. 2007 New nomenclature for chromatin-modifying enzymes. Cell 131 633-636. (doi:10.1016/j.cell. 2007.10.039)

Almstrup K, Nielsen JE, Hansen MA, Tanaka M, Skakkebaek NE \& Leffers H 2004 Analysis of cell-type-specific gene expression during mouse spermatogenesis. Biology of Reproduction 70 1751-1761. (doi:10.1095/biolreprod.103.026575)

Ariel M, Cedar H \& McCarrey J 1994 Developmental changes in methylation of spermatogenesis-specific genes include reprogramming in the epididymis. Nature Genetics 7 59-63. (doi:10.1038/ng0594-59)

Barik S 1996 Site-directed mutagenesis in vitro by megaprimer PCR. Methods in Molecular Biology 57 203-215. (doi:10.1385/0-89603-332-5:203)

Barth TK \& Imhof A 2010 Fast signals and slow marks: the dynamics of histone modifications. Trends in Biochemical Sciences 35 618-626. (doi:10.1016/j.tibs.2010.05.006)

Becker PB \& Horz W 2002 ATP-dependent nucleosome remodeling. Annual Review of Biochemistry 71 247-273. (doi:10.1146/annurev. biochem.71.110601.135400)

Bellve AR 1993 Purification, culture, and fractionation of spermatogenic cells. Methods in Enzymology 225 84-113. (doi:10.1016/00766879(93)25009-Q)

Berg WM, Gebara MM \& McCarrey JR 1993 Sp-1 is required for initiation and stimulation of transcription from the TATA-less PGK-2 promoter Molecular Biology (Life Sci Adv) 12 85-91.

Berger SL 2002 Histone modifications in transcriptional regulation. Current Opinion in Genetics \& Development 12 142-148. (doi:10.1016/S0959437X(02)00279-4)

Boussouar F \& Benahmed M 2004 Lactate and energy metabolism in male germ cells. Trends in Endocrinology and Metabolism 15 345-350. (doi:10.1016/j.tem.2004.07.003)

Brownell JE, Zhou J, Ranalli T, Kobayashi R, Edmondson DG, Roth SY \& Allis CD 1996 Tetrahymena histone acetyltransferase A: a homolog to yeast Gcn $5 p$ linking histone acetylation to gene activation. Cell 84 843-851. (doi:10.1016/S0092-8674(00)81063-6)

Cairns BR 2009 The logic of chromatin architecture and remodelling at promoters. Nature 461 193-198. (doi:10.1038/nature08450)

Chang CJ, Chen TT, Lei HY, Chen DS \& Lee SC 1990 Molecular cloning of a transcription factor, AGP/EBP, that belongs to members of the C/EBP family. Molecular and Cellular Biology 10 6642-6653.

Choe SK, Lu P, Nakamura M, Lee J \& Sagerstrom CG 2009 Meis cofactors control HDAC and CBP accessibility at Hox-regulated promoters during zebrafish embryogenesis. Developmental Cell 17 561-567. (doi:10.1016/j.devcel.2009.08.007)

Clark SJ, Harrison J, Paul CL \& Frommer M 1994 High sensitivity mapping of methylated cytosines. Nucleic Acids Research 22 2990-2997. (doi:10.1093/nar/22.15.2990)

Danshina PV, Geyer CB, Dai Q, Goulding EH, Willis WD, Kitto GB, McCarrey JR, Eddy EM \& O'Brien DA 2010 Phosphoglycerate kinase 2 (PGK2) is essential for sperm function and male fertility in mice. Biology of Reproduction 82 136-145. (doi:10.1095/biolreprod.109.079699)

Eddy EM 2002 Male germ cell gene expression. Recent Progress in Hormone Research 57 103-128. (doi:10.1210/rp.57.1.103)

Fitzgerald J, Hutchison WM \& Dahl HH 1992 Isolation and characterisation of the mouse pyruvate dehydrogenase E1 $\alpha$ genes. Biochimica et Biophysica Acta 1131 83-90. (doi:10.1016/01674781(92)90102-6)
Flaus A \& Owen-Hughes T 2004 Mechanisms for ATP-dependent chromatin remodelling: farewell to the tuna-can octamer? Current Opinion in Genetics \& Development 14 165-173. (doi:10.1016/j.gde. 2004.01.007)

Frommer M, McDonald LE, Millar DS, Collis CM, Watt F, Grigg GW, Molloy PL \& Paul CL 1992 A genomic sequencing protocol that yields a positive display of 5-methylcytosine residues in individual DNA strands. PNAS 89 1827-1831. (doi:10.1073/pnas.89.5.1827)

Gebara MM \& McCarrey JR 1992 Protein-DNA interactions associated with the onset of testis-specific expression of the mammalian Pgk-2 gene. Molecular and Cellular Biology 12 1422-1431. (doi:10.1128/MCB.12.4.1422)

Geyer CB, Kiefer CM, Yang TP \& McCarrey JR 2004 Ontogeny of a demethylation domain and its relationship to activation of tissue-specific transcription. Biology of Reproduction 71 837-844. (doi:10.1095/ biolreprod.104.028969)

He HH, Meyer CA, Shin H, Bailey ST, Wei G, Wang Q, Zhang Y, Xu K, Ni M, Lupien $\mathbf{M}$ et al. 2010 Nucleosome dynamics define transcriptional enhancers. Nature Genetics 42 343-347. (doi:10.1038/ng.545)

Higuchi R 1990 In PCR Protocols: A Guide to Methods and Applications. Eds MA Innis, DH Gelfand, JJ Sninsky \& TJ White. pp 177-183. San Diego, CA: Academic Press, Inc.

Ho L \& Crabtree GR 2010 Chromatin remodelling during development. Nature 463 474-484. (doi:10.1038/nature08911)

Jenuwein T \& Allis CD 2001 Translating the histone code. Science 293 1074-1080. (doi:10.1126/science.1063127)

Kouskouti A \& Talianidis I 2005 Histone modifications defining active genes persist after transcriptional and mitotic inactivation. EMBO Journal 24 347-357. (doi:10.1038/sj.emboj.7600516)

Kouzarides T 2007 Chromatin modifications and their function. Cell 128 693-705. (doi:10.1016/j.cell.2007.02.005)

Kramer JA, McCarrey JR, Djakiew D \& Krawetz SA 1998 Differentiation: the selective potentiation of chromatin domains. Development 125 $4749-4755$.

Kumari M, Stroud JC, Anji A \& McCarrey JR 1996 Differential appearance of DNase I-hypersensitive sites correlates with differential transcription of Pgk genes during spermatogenesis in the mouse. Journal of Biological Chemistry 271 14390-14397. (doi:10.1074/jbc.271.24.14390)

Kurdistani SK, Tavazoie S \& Grunstein M 2004 Mapping global histone acetylation patterns to gene expression. Cell 117 721-733. (doi:10.1016/ j.cell.2004.05.023)

Lachner M, O'Sullivan RJ \& Jenuwein T 2003 An epigenetic road map for histone lysine methylation. Journal of Cell Science 116 2117-2124. (doi:10.1242/jcs.00493)

Lam FH, Steger DJ \& O'Shea EK 2008 Chromatin decouples promoter threshold from dynamic range. Nature 453 246-250. (doi:10.1038/ nature06867)

Lee W, Tillo D, Bray N, Morse RH, Davis RW, Hughes TR \& Nislow C 2007 A high-resolution atlas of nucleosome occupancy in yeast. Nature Genetics 39 1235-1244. (doi:10.1038/ng2117)

Leimgruber E, Seguin-Estevez Q, Dunand-Sauthier I, Rybtsova N, Schmid CD, Ambrosini G, Bucher P \& Reith W 2009 Nucleosome eviction from MHC class II promoters controls positioning of the transcription start site. Nucleic Acids Research 37 2514-2528. (doi:10. 1093/nar/gkp116)

Li XY, Mantovani R, Hooft van Huijsduijnen R, Andre I, Benoist C \& Mathis D 1992 Evolutionary variation of the CCAAT-binding transcription factor NF-Y. Nucleic Acids Research 20 1087-1091. (doi:10.1093/ nar/20.5.1087)

Mantovani R 1999 The molecular biology of the CCAAT-binding factor NF-Y. Gene 239 15-27. (doi:10.1016/S0378-1119(99)00368-6)

Marmorstein R \& Roth SY 2001 Histone acetyltransferases: function, structure, and catalysis. Current Opinion in Genetics \& Development 11 155-161. (doi:10.1016/S0959-437X(00)00173-8)

Marmorstein R \& Trievel RC 2009 Histone modifying enzymes: structures, mechanisms, and specificities. Biochimica et Biophysica Acta $\mathbf{1 7 8 9}$ 58-68. (doi:10.1016/j.bbagrm.2008.07.009)

Mavrich TN, Jiang C, loshikhes IP, Li X, Venters BJ, Zanton SJ, Tomsho LP, Qi J, Glaser RL, Schuster SC et al. 2008 Nucleosome organization in the Drosophila genome. Nature 453 358-362. (doi:10.1038/nature06929)

McCarrey JR 1987 Nucleotide sequence of the promoter region of a tissuespecific human retroposon: comparison with its housekeeping progenitor. Gene 61 291-298. (doi:10.1016/0378-1119(87)90192-2) 
McCarrey JR 1990 Molecular evolution of the human Pgk-2 retroposon. Nucleic Acids Research 18 949-955. (doi:10.1093/nar/18.4.949)

McCarrey JR 1998 Spermatogenesis as a model system for developmental analysis of regulatory mechanisms associated with tissue-specific gene expression. Seminars in Cell \& Developmental Biology 9 459-466. (doi:10.1006/scdb.1998.0199)

McCarrey JR 2013 Toward a more precise and informative nomenclature describing fetal and neonatal male germ cells in rodents. Biology of Reproduction 89 47. (doi:10.1095/biolreprod.113.110502)

McCarrey JR \& Thomas K 1987 Human testis-specific PGK gene lacks introns and possesses characteristics of a processed gene. Nature 326 501-505. (doi:10.1038/326501a0)

McCarrey JR, Berg WM, Paragioudakis SJ, Zhang PL, Dilworth DD, Arnold BL \& Rossi JJ 1992 Differential transcription of Pgk genes during spermatogenesis in the mouse. Developmental Biology 154 160-168. (doi:10.1016/0012-1606(92)90056-M)

McCarrey JR, Kumari M, Aivaliotis MJ, Wang Z, Zhang P, Marshall F \& Vandeberg JL 1996 Analysis of the CDNA and encoded protein of the human testis-specific PGK-2 gene. Developmental Genetics 19 321-332. (doi:10. 1002/(SICI)1520-6408(1996)19:4<321::AID-DVG5>3.0.CO;2-B)

McCarrey JR, Geyer CB \& Yoshioka H 2005 Epigenetic regulation of testisspecific gene expression. Annals of the New York Academy of Sciences 1061 226-242. (doi:10.1196/annals.1336.025)

McNabb DS, Xing Y \& Guarente L 1995 Cloning of yeast HAP5: a novel subunit of a heterotrimeric complex required for CCAAT binding. Genes and Development 9 47-58. (doi:10.1101/gad.9.1.47)

Mori C, Welch JE, Fulcher KD, O'Brien DA \& Eddy EM 1993 Unique hexokinase messenger ribonucleic acids lacking the porin-binding domain are developmentally expressed in mouse spermatogenic cells. Biology of Reproduction 49 191-203. (doi:10.1095/biolreprod49.2.191)

Nagata K, Guggenheimer RA, Enomoto T, Lichy JH \& Hurwitz J 1982 Adenovirus DNA replication in vitro: identification of a host factor that stimulates synthesis of the preterminal protein-dCMP complex. PNAS 79 6438-6442. (doi:10.1073/pnas.79.21.6438)

Nagy A, Gertsenstein M, Vintersten K, Behringer R 2003 Manipulating the Mouse Embryo: A Laboratory Manual. Cold Spring Harbor Laboratory Press. Cold Spring Harbor, NY

Narlikar GJ, Fan HY \& Kingston RE 2002 Cooperation between complexes that regulate chromatin structure and transcription. Cell 108 475-487. (doi:10.1016/S0092-8674(02)00654-2)

Nepveu A 2001 Role of the multifunctional CDP/Cut/Cux homeodomain transcription factor in regulating differentiation, cell growth and development. Gene 270 1-15. (doi:10.1016/S0378-1119(01)00485-1)

Ozsolak F, Song JS, Liu XS \& Fisher DE 2007 High-throughput mapping of the chromatin structure of human promoters. Nature Biotechnology 25 244-248. (doi:10.1038/nbt1279)

Plachetka A, Chayka O, Wilczek C, Melnik S, Bonifer C \& Klempnauer KH 2008 C/EBP $\beta$ induces chromatin opening at a cell-type-specific enhancer. Molecular and Cellular Biology 28 2102-2112. (doi:10. 1128/MCB.01943-07)

Rando OJ \& Chang HY 2009 Genome-wide views of chromatin structure. Annual Review of Biochemistry 78 245-271. (doi:10.1146/annurev. biochem.78.071107.134639)

Robertson KD 2002 DNA methylation and chromatin - unraveling the tangled web. Oncogene 21 5361-5379. (doi:10.1038/sj.onc.1205609)

Robinson MO, McCarrey JR \& Simon MI 1989 Transcriptional regulatory regions of testis-specific PGK2 defined in transgenic mice. PNAS $\mathbf{8 6}$ 8437-8441. (doi:10.1073/pnas.86.21.8437)

Roman C, Platero JS, Shuman J \& Calame K 1990 Ig/EBP-1: a ubiquitously expressed immunoglobulin enhancer binding protein that is similar to C/EBP and heterodimerizes with C/EBP. Genes and Development 4 1404-1415. (doi:10.1101/gad.4.8.1404)

Roy Choudhury D, Small C, Wang Y, Mueller PR, Rebel VI, Griswold MD \& McCarrey JR 2010 Microarray-based analysis of cell-cycle gene expression during spermatogenesis in the mouse. Biology of Reproduction 83 663-675. (doi:10.1095/biolreprod.110.084889)

Santoro C, Mermod N, Andrews PC \& Tjian R 1988 A family of human CCAAT box-binding proteins active in transcription and DNA replication: cloning and expression of multiple cDNAs. Nature 334 218-224. (doi:10.1038/334218a0)
Schones DE, Cui K, Cuddapah S, Roh TY, Barski A, Wang Z, Wei G \& Zhao K 2008 Dynamic regulation of nucleosome positioning in the human genome. Cell 132 887-898. (doi:10.1016/j.cell.2008.02.022)

Sekinger EA, Moqtaderi Z \& Struhl K 2005 Intrinsic histone-DNA interactions and low nucleosome density are important for preferential accessibility of promoter regions in yeast. Molecular Cell 18 735-748. (doi:10.1016/j.molcel.2005.05.003)

Shim EY, Hong SJ, Oum JH, Yanez Y, Zhang Y \& Lee SE 2007 RSC mobilizes nucleosomes to improve accessibility of repair machinery to the damaged chromatin. Molecular and Cellular Biology 27 1602-1613. (doi:10.1128/MCB.01956-06)

Shima JE, McLean DJ, McCarrey JR \& Griswold MD 2004 The murine testicular transcriptome: characterizing gene expression in the testis during the progression of spermatogenesis. Biology of Reproduction 71 319-330. (doi:10.1095/biolreprod.103.026880)

Smith CL \& Peterson CL 2005 ATP-dependent chromatin remodeling. Current Topics in Developmental Biology 65 115-148. (doi:10.1016/ S0070-2153(04)65004-6)

Sterner DE \& Berger SL 2000 Acetylation of histones and transcriptionrelated factors. Microbiology and Molecular Biology Reviews 64 435-459. (doi:10.1128/MMBR.64.2.435-459.2000)

Tang H, Kung A \& Goldberg E 2008 Regulation of murine lactate dehydrogenase C (Ldhc) gene expression. Biology of Reproduction 78 455-461. (doi:10.1095/biolreprod.107.064964)

Turner JM 2007 Meiotic sex chromosome inactivation. Development 134 1823-1831. (doi:10.1242/dev.000018)

Valouev A, Ichikawa J, Tonthat T, Stuart J, Ranade S, Peckham H, Zeng K, Malek JA, Costa G, McKernan K et al. 2008 A high-resolution, nucleosome position map of $C$. elegans reveals a lack of universal sequence-dictated positioning. Genome Research 18 1051-1063. (doi:10.1101/gr.076463.108)

VandeBerg JL 1985 The phosphoglycerate kinase isozyme system in mammals: biochemical, genetic, developmental, and evolutionary aspects. Isozymes: Current Topics in Biological and Medical Research 12 133-187.

VandeBerg JL, Cooper DW \& Close PJ 1973 Mammalian testis phosphoglycerate kinase. Nature: New Biology 243 48-50.

Villagra A, Cruzat F, Carvallo L, Paredes R, Olate J, van Wijnen AJ, Stein GS, Lian JB, Stein JL, Imbalzano AN et al. 2006 Chromatin remodeling and transcriptional activity of the bone-specific osteocalcin gene require CCAAT/enhancer-binding protein $\beta$-dependent recruitment of SWI/SNF activity. Journal of Biological Chemistry 281 22695-22706. (doi:10.1074/jbc.M511640200)

Walter CA, Nasr-Schirf D \& Luna VJ 1989 Identification of transgenic mice carrying the CAT gene with PCR amplification. Biotechniques 7 1065-1070.

Wang PJ, Page DC \& McCarrey JR 2005 Differential expression of sexlinked and autosomal germ-cell-specific genes during spermatogenesis in the mouse. Human Molecular Genetics 14 2911-2918. (doi:10.1093/ hmg/ddi322)

Yoshioka H, Geyer CB, Hornecker JL, Patel KT \& McCarrey JR 2007 In vivo analysis of developmentally and evolutionarily dynamic protein-DNA interactions regulating transcription of the Pgk2 gene during mammalian spermatogenesis. Molecular and Cellular Biology 27 7871-7885. (doi:10.1128/MCB.00990-07)

Yuan GC, Liu YJ, Dion MF, Slack MD, Wu LF, Altschuler SJ \& Rando OJ 2005 Genome-scale identification of nucleosome positions in $S$. cerevisiae. Science 309 626-630. (doi:10.1126/science.1112178)

Zhang LP, Stroud JC, Walter CA, Adrian GS \& McCarrey JR 1998 A genespecific promoter in transgenic mice directs testis-specific demethylation prior to transcriptional activation in vivo. Biology of Reproduction 59 284-292. (doi:10.1095/biolreprod59.2.284)

Zhang LP, Stroud J, Eddy CA, Walter CA \& McCarrey JR 1999 Multiple elements influence transcriptional regulation from the human testisspecific PGK2 promoter in transgenic mice. Biology of Reproduction 60 1329-1337. (doi:10.1095/biolreprod60.6.1329)

Received 15 July 2013

First decision 15 August 2013

Revised manuscript received 21 August 2013

Accepted 2 September 2013 